\title{
PEG-Derivatized Dual-Functional Nanomicelles for Improved Cancer Therapy
}

\author{
Yanping $\mathrm{Li}^{1}$, Ting Zhang ${ }^{2}$, Qinhui Liu ${ }^{1}$ and Jinhan $\mathrm{He}^{1,2 *}$ \\ ${ }^{1}$ Laboratory of Clinical Pharmacy and Adverse Drug Reaction, West China Hospital of Sichuan University, Chengdu, China, \\ ${ }^{2}$ Department of Pharmacy, West China Hospital of Sichuan University, Chengdu, China
}

OPEN ACCESS

Edited by:

Ali H. Eid,

American University of Beirut,

Lebanon

Reviewed by:

Baolin Guo,

Xi'an Jiaotong University, China

Song Li,

University of Pittsburgh,

United States

*Correspondence:

Jinhan He

jinhanhe@scu.edu.cn

Specialty section:

This article was submitted to

Translational Pharmacology,

a section of the journal

Frontiers in Pharmacology

Received: 16 April 2019

Accepted: 24 June 2019

Published: 19 July 2019

Citation:

Li Y, Zhang T, Liu Q and He J (2019) PEG-Derivatized Dual-

Functional Nanomicelles for Improved Cancer Therapy.

Front. Pharmacol. 10:808. doi: 10.3389/fphar.2019.00808
Polymeric micelles have attracted considerable attention for effective delivery of poorly water-soluble cancer drugs. Polyethylene glycol (PEG), which has been approved for human use by the US Food and Drug Administration, is the most commonly used hydrophilic component of polymeric micelles because it is biocompatible and biodegradable. One disadvantage of traditional polymeric micelles is that they include a large amount of inert carrier materials, which do not contribute to therapeutic activity but increase cost and toxicity risk. A better alternative may be "dual-functional" micellar carriers, in which the hydrophobic carrier material (conjugated to PEG) has intrinsic therapeutic activity that complements, or even synergizes with, the antitumor activity of the drug cargo. This review summarizes recent progress in the development of PEG-derivatized dual-functional nanomicelles and surveys the evidence of their feasibility and promise for cancer therapy.

Keywords: polyethylene glycol (PEG), dual-functional nanomicelles, cancer therapy, multidrug resistance, drug loading capacity, cancer immunochemotherapy

\section{INTRODUCTION}

Cancer has become the "first killer" that threatens human health (Siegel et al., 2017; Smith et al., 2017; Torre et al., 2017). Chemotherapy, one of the most important tools in clinical cancer treatment, inhibits growth of primary tumors and suppresses proliferation of metastatic tumor cells (Chabner and Roberts, 2005). Although many anticancer drugs have been approved, their clinical application is often compromised by poor water solubility, short circulation time, and serious systemic side effects (Shi et al., 2016; Youn and Bae, 2018). Nanomaterials have been widely used in cancer therapy (Wicki et al., 2015). Various nanocarriers, including nanoparticles (Geszke-Moritz and Moritz, 2016), liposomes (Cheng and Ji, 2019), micelles (Cagel et al., 2017), and dendrimers (Ray et al., 2018), have opened up new possibilities for sustained, controlled, and targeted cancer drug delivery, achieving higher effective drug concentrations at the tumor site with fewer off-target side effects. In particular, polymeric micelles have attracted attention as multifunctional drug delivery systems for poorly water-soluble agents (Zhang et al., 2014h; Biswas et al., 2016).

Polymeric micelles are self-assembling nanoparticles $(5-200 \mathrm{~nm})$ composed of amphiphilic polymers. The structure of polymeric micelles follows and exemplifies the similar structure of micelles proposed as per different micellar theories (Gothwal et al., 2016). It is composed of a "core," which is usually a hydrophobic section while the exterior, which is also known as "shell," represents a hydrophilic block of the copolymer structure (Figure 1) (Mohamed et al., 2014; Zhang et al., 2014d). Polymeric micelles are easy to prepare, highly biocompatible, and quite efficient at encapsulating and delivering drugs in the body (Gong et al., 2012). Polymeric micelles can encapsulate 




FIGURE 1 | General structure of polymeric micelles loaded with hydrophobic drug.

water-insoluble agents in their hydrophobic core, improving bioavailability (Kedar et al., 2010; Tanbour et al., 2016). A hydrophilic shell of polyethylene glycol (PEG) can significantly prolong the circulation time of polymeric micelles in the blood (Suk et al., 2016). Polymeric micelle in the 10-100 $\mathrm{nm}$ range can pass through the leaky vasculature and passively accumulate in tumors via the enhanced permeability and retention effect (EPR) (Maeda et al., 2009; Fang et al., 2011; Maeda et al., 2013).

PEG, which has been approved by the US Food and Drug Administration (FDA) for use in human, is the most commonly used hydrophilic component of polymeric micelles (Molineux, 2002; Duncan, 2014; Qu et al., 2018). It is biodegradable and biocompatible because it does not form toxic metabolites, and it is commercially available in molecular weights ranging from 500 to 20,000 Da. Surface modification of PEG-based nanocarriers can reduce interactions with plasma proteins and nonspecific uptake by the reticuloendothelial system, prolonging time in systemic circulation (Bae and Kataoka, 2009; Wang et al., 2018a). The multifunctionality of PEG allows multiple drug or targeting molecules to be conjugated to the same polymer chain. Currently, several PEG-derivatized polymeric micelles carrying anti-cancer drugs are under clinical evaluation, including NK012, NK105, SP1049C, NK911, and Genexol-PM (Cabral and Kataoka, 2014; Mohamed et al., 2014; Deshmukh et al., 2017). In fact, regulatory authorities in South Korea have approved Genexol-PM for use against breast cancer.

In the "hydrophilic shell-hydrophobic core" architecture of polymeric micelles, the hydrophobic core provides a loading space for poorly water-soluble drugs (Zhang et al., 2014d). The polymers most commonly used to build the hydrophobic core are polyesters and polyamides, such as polycaprolactone, poly(lactic acid), poly(glycolic acid), and poly(L-histidine) (Zhang and Zhuo, 2005; Zhang et al., 2014a; Zhang et al., 2014c). Most of these hydrophobic components are inert carrier materials without therapeutic activity. In other words, they add to the cost and toxicity risk of the drug delivery system, without contributing to therapeutic efficacy (Qu et al., 2017b). This has led researchers to explore nanocarriers that themselves have therapeutic effects.

Since Ringsdorf proposed the concept of "polymeric prodrug" in 1975, the utility of polymer-drug conjugates in clinical therapy has been well demonstrated (Hoste et al., 2004; Ringsdorf, 2010). Interestingly, hydrophobic drugs conjugated to hydrophilic polymers can self-assemble into micelles, which can then be loaded with another therapeutic molecule (Ulbrich and Subr, 2004; Greco and Vicent, 2008). Numerous bioactive hydrophobic agents have been conjugated to PEG to form so-called "dualfunctional" micellar carriers, which have intrinsic antitumor activity and that deliver anti-tumor drug cargo (Mi et al., 2011; Huang et al., 2012; Chung et al., 2014; Zhang et al., 2014e). PEGderivatized dual-functional micelles are typically prepared with one of two types of hydrophobic material (Qu et al., 2017b): anti-cancer natural products not yet used clinically, such as vitamin E succinate, (-)-epigallocatechin-3-gallate, embelin, and S-trans,trans-farnesylthiosalicylic acid, or anti-cancer molecules already established in the clinic, such as camptothecin (CPT), doxorubicin (DOX), paclitaxel (PTX), and docetaxel (Figure 2).

In this review, we summarize recent progress in PEG-derivatized dual-functional micellar carriers and their application in cancer therapy. Strategies to improve carrier-drug interactions are discussed because two challenges in the development of polymeric micelles are their drug-loading capacity and stability. Recent developments in exploiting dual-functional carriers for therapies combining immuno- and chemotherapy are also surveyed.

\section{PEG-DERIVATIZED DUAL-FUNCTIONAL MICELLES WITH INTRINSIC ANTI- CANCER ACTIVITY}

\section{PEG-Derivatized Vitamin E}

Vitamin E succinate (D-a-tocopherol, $\boldsymbol{\alpha}$-TOS) is a derivative of vitamin $\mathrm{E}$ that shows activity against various types of cancers, including breast, lung, and prostate (Malafa and Neitzel, 2000; Malafa et al., 2002; Kline et al., 2004). a-TOS can selectively kill tumor cells without affecting normal cells by inhibiting angiogenesis, suppressing activation of NF- $\kappa \mathrm{B}$, and generating reactive oxygen species (Dong et al., 2007; Jin et al., 2014). It can also enhance the cytotoxicity of PTX and DOX (Kanai et al., 2010), and it can inhibit P-glycoprotein (P-gp) to overcome multidrug resistance (MDR) (Constantinides et al., 2006).

The poor water solubility of $\alpha$-TOS has limited its use in vivo, leading researchers to explore possibilities with $\mathrm{D}$ - $\alpha$-tocopheryl PEG succinate (vitamin E TPGS, or simply TPGS), which is a water-soluble derivative of $\alpha$-TOS generated by esterification with PEG (Youk et al., 2005). TPGS acts as a nonionic surfactant: it exhibits amphipathic properties and can form micelles in aqueous media at a critical micelle concentration (CMC) of $0.2 \mathrm{mg} / \mathrm{ml}$. It has been investigated as an absorption enhancer, emulsifier, solubilizer, additive and permeation enhancer, and stabilizer (Zhang et al., 2012; Guo et al., 2013). TPGS also inhibits P-gp-mediated drug efflux by inhibiting the ATPase of P-gp and mitochondrial respiratory complex II (Dong et al., 2008; Collnot et al., 2010). The relatively high CMC of TPGS and its relatively 
<smiles>Cc1c(C)c2c(c(C)c1OC(=O)CCC(=O)O)CCC(C)(CCCC(C)CCCC(C)CCCC(C)C)O2</smiles><smiles>CCCCCCCCCCCC1=C(O)C(=O)C=CC1=O</smiles>

Vitamin E succinate<smiles>CC(C)=CCC/C(C)=C/CC/C(C)=C/CSc1ccccc1C(=O)O</smiles>

S-trans, trans-farnesylthiosalicylic acid<smiles>CCC1(O)C(=O)OCc2c1cc1n(c2=O)Cc2cc3ccccc3nc2-1</smiles>

Camptothecin

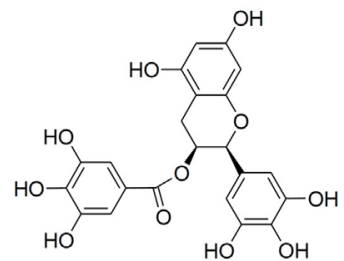

(-)-Epigallocatechin-3-Ogallate

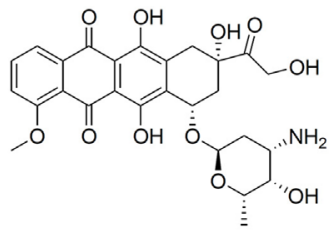

Doxorubicin



Paclitaxel

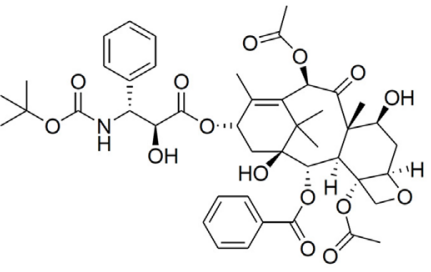

Docetaxel

FIGURE 2 | Chemical structure of hydrophobic domains in polyethylene glycol (PEG)-derivatized dual-functional micellar carriers.

short PEG chains mean that TPGS-based micelles usually leave the circulation quickly and accumulate in the liver and spleen (Tan et al., 2017; Yang et al., 2018a). Therefore, TPGS is usually mixed with other lipids or copolymers to form micelles.

Research groups have taken different approaches to improving the properties of TPGS as a micelle carrier (Figure 3). Conjugating tocopheryl succinate to PEG 2000 leads to TPGS $_{2 \mathrm{~K}}$, which has a much lower CMC than TPGS, allowing formation of stable drugloaded micelles without addition of other lipids or polymers. For example, one group developed $\mathrm{TPGS}_{2 \mathrm{~K}}$ polymer-based micelles with a CMC of only $0.0219 \mathrm{mg} / \mathrm{ml}$ (Mi et al., 2011). Docetaxel was successfully loaded in $\mathrm{TPGS}_{2 \mathrm{~K}}$ micelles to form a uniform sphere with an average diameter of $15 \mathrm{~nm}$. In vitro antitumor results showed that docetaxel-loaded TPGS2K micelles dramatically decreased the $\mathrm{IC}_{50}$ values of MCF-7 cells $(0.526 \mathrm{~g} / \mathrm{ml})$ compared with that of the free docetaxel $(103.4 \mathrm{~g} / \mathrm{ml})$, indicating a synergistic therapeutic effect between $\mathrm{TPGS}_{2 \mathrm{~K}}$ and docetaxel. Another group conjugated PEG to two vitamin E molecules to form star-shaped copolymer $\mathrm{PLV}_{2 \mathrm{~K}}$ micelles with a CMC of only $1.14 \mu \mathrm{g} / \mathrm{ml}$ (Wang et al., 2012). DOX was encapsulated into the hydrophobic core of $\mathrm{PLV}_{2 \mathrm{~K}}$ with encapsulation efficiency as high as $94.5 \%$, and the drug-loaded micelles inhibited growth of 4T1 breast cancer tumors in mice more effectively than free DOX or DOX-loaded in TPGS.

Screening two PEG lengths $\left(\mathrm{PEG}_{2 \mathrm{~K}}\right.$ or $\left.\mathrm{PEG}_{5 \mathrm{~K}}\right)$ and two molar ratios of PEG to vitamin $\mathrm{E}(1: 1$ or $1: 2)$ identified $\mathrm{PEG}_{5 \mathrm{~K}}-\mathrm{VE}_{2}$ micelles comprising one $\mathrm{PEG}_{5 \mathrm{~K}}$ and two vitamin $\mathrm{E}$ molecules as having the lowest CMC and most efficient PTX loading ( $\mathrm{Lu}$ et al., 2013a; Lu et al., 2014c). Loading PTX into $\mathrm{PEG}_{5 \mathrm{~K}}-\mathrm{VE}_{2}$ inhibited tumor growth in mice significantly better than loading it into $\mathrm{PEG}_{2 \mathrm{~K}}-\mathrm{VE}$ or $\mathrm{PEG}_{5 \mathrm{~K}}-\mathrm{VE}_{2}$, or than using Taxol. Our group has analyzed how the molar ratio of PEG to vitamin $\mathrm{E}$ affects the stability, drug loading capacity, and tumor targeting efficiency of TPGS-based micelles in vitro and in vivo (Li et al., 2016a; Li et al., 2016b). PAMV 6 , which is formulated with a 1:6 molar ratio of PEG to vitamin E and shows a wheat-like structure, showed the lowest CMC, greatest stability in serum, and highest tumor distribution and retention. Moreover, $\mathrm{PAMV}_{6}$ inhibits $\mathrm{P}$-gp efflux activity, not by affecting P-gp expression, but by decreasing mitochondrial membrane potential and intracellular levels of ATP (Li et al., 2016a). As a result, pirarubicin-loaded $\mathrm{PAMV}_{6}$ micelles inhibited the growth of MCF-7/ADR xenograft tumors in mice significantly better than free pirarubicin, with significantly less systemic and organ-specific toxicity.

\section{PEG-Derivatized EGCG}

The most abundant catechin in green tea, (-)-epigallocatechin3-gallate (EGCG), shows activity against cancer, diabetes, neurodegenerative disease, stroke, obesity, and other disorders (Chakrawarti et al., 2016; Song et al., 2017). EGCG can inhibit tumor growth and metastasis by interrupting key signaling and 




metabolic pathways that support cancer cell survival without damaging normal cells (Shankar et al., 2007; Wang et al., 2018b). For example, EGCG can down-regulate PEA15 expression and enhance TRAIL-mediated apoptosis in tumor cells (Siegelin et al., 2008; Le et al., 2018). EGCG interacts with the estrogen receptor to inhibit estrogen-induced proliferation of breast cancer cells and sensitize hormone-responsive tumors to drugs such as tamoxifen that target steroid receptors (Farabegoli et al., 2007; Tu et al., 2011).

Despite its clear therapeutic effects, EGCG remains far from clinical use, in large part because of its low stability and bioavailability. The several hydroxyl groups in EGCG make it highly hydrophilic, which resulted in short circulation halftime. One group developed a micellar nanocomplex (MNC) comprising two EGCG derivatives that bind to proteins in a spatially ordered structure (Chung et al., 2014). MNCs selfassemble in two steps: first, oligomerized EGCG (OEGCG) complexes with the humanized monoclonal therapeutic antibody Herceptin (trastuzumab) to form a core; second, PEG-EGCG assembles as a shell around this core. The resulting MNC is monodisperse and spherical, with a mean diameter of about $90 \mathrm{~nm}$ and good stability in serum at $37^{\circ} \mathrm{C}$ for 15 days. Both in vitro and in vivo therapeutic studies showed that HerceptinMNC had superior anti-tumor effects to free Herceptin. While Herceptin on its own shows anti-tumor activity, it synergizes with the EGCG within MNC to cause even greater inhibition, with a combination index of 0.93 . Similarly, replacing Herceptin with interferon $\alpha-2 a$ generates an MNC that inhibits the growth of HAK-1B human liver cancer cells more than free interferon $\alpha-2 a$, with a combination index of 0.46 .

EGCG inhibits P-gp (Jodoin et al., 2002) and can sensitize drugresistant tumor cells to DOX and increase DOX accumulation in MDR cells (Liang et al., 2010; Song et al., 2017). Thus, combination therapy with EGCG and DOX may simultaneously overcome DOX-induced cardiotoxicity and MDR. Special methods are needed to co-load DOX and EGCG into micelles, since DOX is hydrophobic while EGCG is hydrophilic and unstable. To achieve such co-loading, a novel green tea catechin-based 
polyion complex was developed in which DOX and EGCG were co-loaded via electrostatic interactions as well as interactions between EGCG and poly(ethylene glycol)-block-poly(lysineco-lysine-phenylboronic acid) (Cheng et al., 2016). This allowed DOX to be loaded into the micelles with a drug loading capacity of $12.4 \%$ and drug loading efficiency of $55 \%$. The ability of EGCG to scavenge oxygen free radicals and inhibit P-gp means that these vesicles may simultaneously overcome DOX-induced cardiotoxicity and MDR (Mei et al., 2004; Yao et al., 2017).

\section{PEG-Derivatized Embelin}

Embelin (2,5-dihydroxy-3-undecyl-1,4-benzoquinone), a major active constituent of the Embelia ribes Burn plant, possesses analgesic, anti-diabetic, anti-inflammatory, and hepatoprotective activities (Chitra et al., 1994; Naik et al., 2013; Peng et al., 2014). It also inhibits growth of breast, colon, prostate, and pancreatic tumors via several different mechanisms. In most cases, the compound induces intrinsic or extrinsic apoptotic cell death and modulates signaling pathways involving NF- $\mathrm{B}, \mathrm{p} 53, \mathrm{PI} 3 \mathrm{~K} /$ AKT, and STAT3 (Heo et al., 2011; Kim et al., 2013; Ko et al., 2018). Interestingly, in silico screening predicts that embelin inhibits the X-linked inhibitor of apoptosis protein (XIAP), which is over-expressed in a variety of cancers, especially drugresistant ones (Nikolovska-Coleska et al., 2004; Hussain et al., 2017). Several synthetic peptide inhibitors of XIAP have been reported, and some are in clinical trials, but embelin would be the only naturally occurring non-peptide XIAP inhibitor reported so far.

Embelin is poorly water-soluble and has limited oral bioavailability. Modifying it with PEG can significantly increase its water solubility, and the resulting PEG-embelin conjugates can self-assemble to form micelles and efficiently encapsulate hydrophobic drugs such as PTX and DOX (Huang et al., 2012). Screening two PEG lengths $\left(\mathrm{PEG}_{3.5 \mathrm{~K}}\right.$ or $\left.\mathrm{PEG}_{5 \mathrm{~K}}\right)$ and two molar ratios of PEG to $\mathrm{EB}(1: 1$ or $1: 2)$ showed that $\mathrm{PEG}_{5 \mathrm{~K}}-\mathrm{EB}_{2}$, in which two embelin molecules were linked via aspartic acid to one PEG $_{5 \mathrm{~K}}$, showed the lowest CMC and highest PTX loading efficiency (Lu et al., 2013b). When these micelles were loaded with PTX, the embelin and PTX synergized to inhibit cancer cell growth in vitro even when PTX were present at nanomolar concentrations. The same micelles also inhibited growth of 4T1 breast cancer tumors and PC-3 prostate cancer tumors in mice better than Taxol, with minimal toxicity.

To improve the targeting ability of $\mathrm{PEG}_{5 \mathrm{~K}}-\mathrm{EB}_{2}$ micelles, folic acid (FA) was coupled to the surface and the resulting FA-PEG ${ }_{5 \mathrm{~K}}-\mathrm{EB}_{2}$ were able to readily self-assemble to form nanomicelles with a particle diameter around $20 \mathrm{~nm}$ (Lu et al., 2014b). FA-PEG ${ }_{5 \mathrm{~K}}-\mathrm{EB}_{2}$ significantly facilitated the intracellular uptake of DOX over free DOX and Doxil in breast cancer cells 4T1.2, and drug-resistant cells NCI/ADR-RES. Consistent with better tumor targeting, the FA-decorated micelles inhibited the growth of 4T1.2 metastatic breast cancer tumors in mice significantly more than free DOX, Doxil or the micelles without FA, and with lower toxicity.

PEG-embelin micelles, in addition to enhancing the antitumor efficacy of PTX or DOX, can also inhibit P-gp ATPase activity analogously to TPGS and thereby can sensitize drugresistant NCI/ADR-RES cells to DOX (Lu et al., 2013b; Lu et al., 2014b). Further studies should clarify whether PEG-embelin micelles act as a non-competitive or competitive inhibitor of the P-gp ATPase.

\section{PEG-Derivatized Farnesylthiosalicylic Acid}

S-trans,trans-farnesylthiosalicylic acid (FTS) is a synthetic farnesylcysteine mimetic with strong potential to be an effective cancer drug (Kloog and Cox, 2000; Erlich et al., 2006). As a first-in-class Ras inhibitor, it is in phase II clinical trials to treat pancreatic cancer and lung adenocarcinoma (Riely et al., 2011; Laheru et al., 2012). FTS may also be effective against other cancers in which mutated Ras proteins are constitutively active (Simanshu et al., 2017), and it so far has shown minimal side effects (Gana-Weisz et al., 2002). FTS can also suppress cancer cell growth and proliferation by inhibiting mTOR, especially in endocrine-resistant breast cancer (Mcmahon et al., 2005).

Its long hydrophobic chains make FTS poorly water-soluble, so it is usually PEGylated when forming micelles (Figure 4). For example, conjugation two FTS to PEG via a labile ester linkage readily forms $\mathrm{PEG}_{5 \mathrm{~K}}-\mathrm{FTS}_{2}(\mathrm{~L})$ micelles in aqueous solution, which inhibit tumor growth in mice to a similar extent as free FTS (Zhang et al., 2013). Loading these micelles with PTX or curcumin led to synergy between these compounds and the FTS, such that micelle cytotoxicity was higher than with PTX or curcumin on their own (Zhang et al., 2013; Chen et al., 2014). Breaking of the linkage between PEG and FTS appears to be critical for its antitumor activity: replacing the ester linkage with a more stable amide linkage resulted in significantly lower cytotoxicity (Zhang et al., 2013). It is likely that FTS is much more readily released from $\mathrm{PEG}_{5 \mathrm{~K}}-\mathrm{FTS}_{2}(\mathrm{~L})$ than $\mathrm{PEG}_{5 \mathrm{~K}}-\mathrm{FTS}_{2}(\mathrm{~S})$ with a stable amide linkage. In vitro, $\mathrm{PEG}_{5 \mathrm{~K}}-\mathrm{FTS}_{2}(\mathrm{~L})$ alone was much more active than $\mathrm{PEG}_{5 \mathrm{~K}}-\mathrm{FTS}_{2}(\mathrm{~S})$ in antitumor activity in both $4 \mathrm{~T} 1.2$ and HCT116 cell lines. In vivo, PTX formulated in $\mathrm{PEG}_{5 \mathrm{~K}}-\mathrm{FTS}_{2}(\mathrm{~L})$ showed antitumor activity that is more potent than that of Taxol or PTX/ $\mathrm{PEG}_{5 \mathrm{~K}}-\mathrm{FTS}_{2}(\mathrm{~S})$. Glutathione is present in tumors at much higher concentrations than in extracellular fluids (Saito et al., 2003; Zhang et al., 2018b), so coupling the FTS to PEG via a disulfide linkage can lead to greater release of FTS inside tumor cells and therefore to greater cytotoxicity than either Taxol or PTX (Zhang et al., 2014g).

Screening of two weights of PEG $\left(\mathrm{PEG}_{2 \mathrm{~K}} v s . \mathrm{PEG}_{5 \mathrm{~K}}\right)$ and two molar ratios PEG: FTS (1:2 or 1:4) identified $\mathrm{PEG}_{5 \mathrm{~K}^{-}}$ $\mathrm{FTS}_{4}$ as the stablest and most cytotoxic micelles against 4T1.2 breast cancer tumors in mice (Zhang et al., 2014e). Adding the 9-fluorenylmethoxycarbony (Fmoc) moiety to these micelles significantly improved the loading capacity of PTX and DOX as well as efficacy against breast and prostate cancer tumors in mice (Zhang et al., 2014f). Incorporating a disulfide linkage into Fmoc-modified $\mathrm{PEG}_{5 \mathrm{~K}}-\mathrm{FTS}_{2}$ micelles reduced the CMC to $0.02 \mu \mathrm{M}$, which was 10 -fold lower than the CMC of micelles without either the Fmoc moiety or disulfide linkage (Xu et al., 2017). It also increased accumulation inside prostate cancer tumors in mice by two- to three-fold. The disulfide linkage also increased the cytotoxicity in vitro and in vivo when Fmoc-modified micelles were loaded with PTX. These studies indicate that PEG-FTS is 


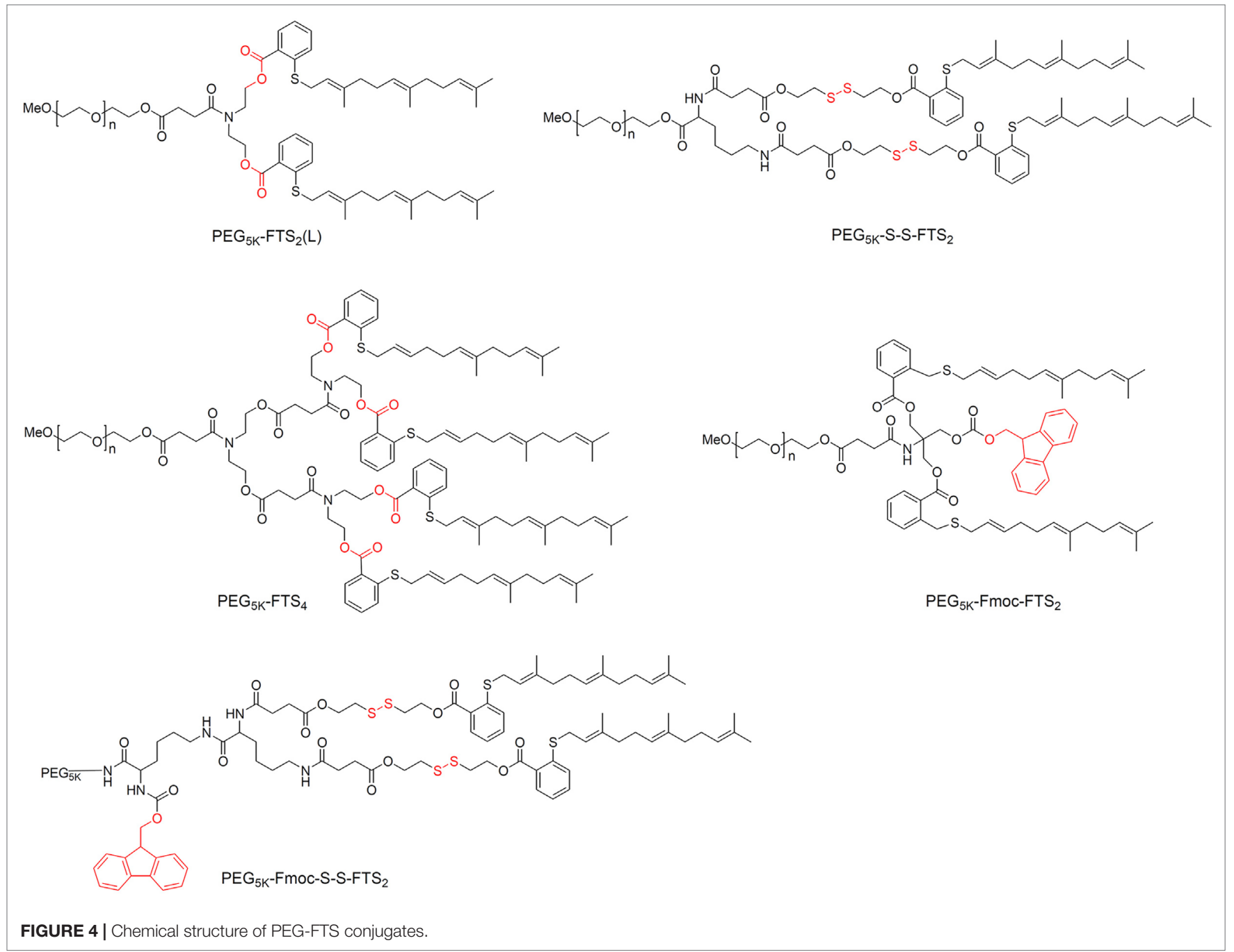

an effective dual-functional carrier that can synergize with co-delivered anti-cancer agents.

\section{PEG-Derivatized Anticancer Drugs}

Most small-molecule anti-cancer drugs are hydrophobic. Their water solubility and circulation time can be improved by creating PEGylated prodrug copolymers that self-assemble into micelles. These PEG-drug conjugates can also be used to carry additional chemotherapeutic agents (Table 1). Below, we discuss only PEGylated prodrug complexes to which additional drugs are added. PEGylated drug complexes without further drug addiction have been reviewed elsewhere.

The natural cytotoxic quinolone alkaloid CPT inhibits DNA topoisomerase I, making it effective against a wide spectrum of cancers (Gromova et al., 1990; Pizzolato and Saltz, 2003; Zunino and Pratesi, 2004). However, the clinical use of CPT is limited by its extremely hydrophobicity and low stability in vivo (Koo et al., 2005; Botella and Rivero-Buceta, 2017). A CPT-PEGCPT prodrug has been prepared by conjugating two molecules of CPT to the ends of PEG via degradable ester linkage (Dong et al., 2012). This complex, which can accommodate CPT up to $41 \%$, self-assembled into micelles with a diameter of $50 \mathrm{~nm}$. DOX was loaded into the micelles with high capacity, and the complex showed greater cytotoxicity than free DOX. The increased cytotoxicity might be induced by the combined effect of both DOX and CPT. Further, they introduced redoxresponsive disulfide linkers and prepared a micellar system (CPT-SS-PEG-CPT) to achieve an aim of rapidly releasing the native CPT in tumor-relevant reductive conditions ( $\mathrm{Li}$ et al., 2011). An amphiphilic prodrug of CPT has been prepared by polymerizing $\gamma$-CPT glutamate $\mathrm{N}$-carboxyanhydride with $\mathrm{mPEG}$ via $\mathrm{pH}$-sensitive boronate ester bonds (Gao et al., 2018). The resulting prodrug self-assembled into micelles, simultaneously encapsulating DOX. These micelles showed sustained drug release during $48 \mathrm{~h}$, which increased when $\mathrm{pH}$ was reduced from 7.4 to 6.0. This approach may promote uptake of the micelles and drug release specifically in the acidic tumor microenvironment.

PTX, isolated from Taxus brevifolia, is one of the most effective chemotherapeutic drugs against ovarian, lung, breast, 
TABLE 1 | Polyethylene glycol (PEG)-derivatized anticancer drug as dual-functional micellar carrier.

\begin{tabular}{|c|c|c|c|c|}
\hline Self-assembled prodrugs & Hydrophobic drug & Co-loaded drug & In vitro/in vivo experimental model & References \\
\hline CPT-SS-PEG-SS-CPT & Camptothecin & Camptothecin & HepG2 human hepatoma cell model & (Li et al., 2011) \\
\hline CPT-PEG-CPT & Camptothecin & Doxorubicin & Human cervical cancer Hela cells & (Dong et al., 2012) \\
\hline mPEG-BC-PGluCPT & Camptothecin & Doxorubicin & HepG2 and HL-7702 cells & (Gao et al., 2018) \\
\hline P(CPTMA-coPEMA) & Camptothecin & Glucose oxidase & A549 tumors & (Li et al., 2017) \\
\hline PEG-bPTCPT & Camptothecin & $\beta$-lapachone & $\begin{array}{l}\text { Mouse breast cancer } 4 \mathrm{~T} 1 \text { cell line and } 4 \mathrm{~T} 1 \text { tumor- } \\
\text { bearing mice }\end{array}$ & (Yin et al., 2019) \\
\hline PEG-PTX & Paclitaxel & Paclitaxel & $\begin{array}{l}\text { MCF- } 7 \text { cells and mouse xenograft tumor model } \\
\text { bearing MCF- } 7 \text { cells }\end{array}$ & (Lu et al., 2014a) \\
\hline PEG-acetal-PTX & Paclitaxel & Paclitaxel & HeLa and MDA-MB-231 cells & (Huang et al., 2018) \\
\hline mPEG-b-DOX & Doxorubicin & Verapamil & MCF-7/ADR cell line & (Zhao et al., 2015) \\
\hline PEG-CH = N-DOX & Doxorubicin & $\begin{array}{l}\text { 7-ethyl-10-hydroxyl- } \\
\text { camptothecin }\end{array}$ & $\begin{array}{l}\text { MCF- } 7 \text { cells and mouse xenograft tumor model } \\
\text { bearing MCF- } 7 \text { cells }\end{array}$ & (Sun et al., 2018b) \\
\hline PEG-DTX & Docetaxel & Docetaxel & $\begin{array}{l}\text { H460 human non-small cell lung, SKOV-3 human } \\
\text { ovarian and MCF-7 human breast cancer cells }\end{array}$ & (Liu et al., 2008) \\
\hline PEG-CCM@APTES-COF-1 & Curcumin & Doxorubicin & $\begin{array}{l}\text { HeLa cells and HeLa cell xenograft tumor mice } \\
\text { model }\end{array}$ & (Zhang et al., 2018a) \\
\hline PEG-Fmoc-GA & Glycyrrhizic acid & Doxorubicin & HepG2 cells human liver cancer xenograft model & (Yang et al., 2018b) \\
\hline
\end{tabular}

and other cancers (Wani et al., 1971; Blair and Deeks, 2015; Bourgeois-Daigneault et al., 2016). Its aqueous solubility is only about $0.3 \mathrm{mg} / \mathrm{ml}$, so it is solubilized with polyoxyethylenated castor oil (Cremophor EL) in the commercial formulation of PTX, called Taxol. Cremophor EL can cause serious hypersensitivity, neurotoxicity, and nephrotoxicity, which severely limit the success of PTX chemotherapy (Singla et al., 2002; Nehate et al., 2014). To avoid these problems, mPEG5000 and PTX have been conjugated via succinic anhydride as linker, giving a water-soluble PTX prodrug (Greenwald et al., 1996). Although this prodrug appears to have negligible anti-tumor activity because PTX release is too low (Liang et al., 2012), the prodrug can complex with free PTX to form spherical particles of 100-200 nm ( $\mathrm{Lu}$ et al., 2014a). These particles inhibited the growth of MCF-7 tumors in mice significantly better than Taxol, and with less toxicity. To allow breakage of the PEGPTX bond under certain conditions, PEG and PTX have been conjugated using an acetal linker that cleaves preferentially when exposed to endosomal pH (Huang et al., 2018). This prodrug self-assembles into micelles and can encapsulate free PTX into the hydrophobic core, such that the total PTX concentration in the micelles reaches a capacity of $60.3 \%$. These PTX-loaded micelles inhibited HeLa and MDA-MB-231 cells more than free PTX.

\section{PEG-DERIVATIZED DUAL-FUNCTIONAL MICELLES FOR IMMUNOCHEMO- THERAPY}

Accumulation evidence suggests that chemotherapy-induced immune responses contribute to the overall anti-tumor effects of chemotherapy (Vanneman and Dranoff, 2012; Bracci et al., 2014; Kumar et al., 2017). However, cancer treatment also up-regulates various negative feedback mechanisms that limit the effectiveness of chemotherapy-elicited immune responses as well as other immunotherapies (Curran et al., 2010; Jiang et al.,
2019). For example, indoleamine 2,3-dioxygenase (IDO) is a negative feedback protein that helps tumors evade the immune system, grow, and metastasize (Soliman et al., 2010; Ricciuti et al., 2019; Zhu et al., 2019); IDO causes immunosuppressive effects by inhibiting $\mathrm{T}$ cell differentiation and proliferation (Uyttenhove et al., 2003; Zamanakou et al., 2007). Reversing these negative feedback mechanisms may have anti-tumor effects. NLG919, a highly selective IDO inhibitor with a median effect concentration of $75 \mathrm{nM}$, promotes growth of T and natural killer cells, increases interferon production, and reduces conversion to a regulatory $\mathrm{T}$ cell phenotype (Mautino et al., 2013; Li et al., 2014; Meng et al., 2017). NLG919 is poorly water soluble, and it cannot be simply co-delivered as a mixture with drugs because of differences in physico-chemical and pharmacokinetic profiles (Liu et al., 2010).

NLG919 has been conjugated with PEG in a dual-functional, immunostimulatory micelle in which the Fmoc group was introduced to improve drug loading capacity and formulation stability (Chen et al., 2016). The resulted $\mathrm{PEG}_{2 \mathrm{~K}}-\mathrm{Fmoc}-\mathrm{NLG}$ micelles self-assembled in aqueous solutions to form particles of about $90 \mathrm{~nm}$ with a CMC of $0.737 \mathrm{mM}$. It's found that $\mathrm{PEG}_{2 \mathrm{~K}^{-}}$ Fmoc-NLG with a relatively labile ester linkage well retained the pharmacological activity of NLG919 and significantly enhanced T-cell immune responses. The micelles could also be loaded with several common drugs: PTX, docetaxel, DOX, gefitinib, imatinib, and curcumin. PTX-loaded $\mathrm{PEG}_{2 \mathrm{~K}}$-Fmoc-NLG micelles were delivered intravenously into mice bearing breast cancer tumors or melanomas, and they showed significantly greater anti-tumor response than free PTX or the empty micelles without PTX.

These PTX-loaded micelles also enhanced anti-tumor immune responses, yet they triggered the counter-productive accumulation of myeloid-derived suppressor cells (MDSCs), which maintain a highly immunosuppressive tumor microenvironment (Pastaki Khoshbin et al., 2019; Safari et al., 2019; Groth et al., 2019). MDSCs can induce immunosuppression by up-regulating inducible nitric oxide synthase and arginase I, thereby inhibiting T-cell function (Meirow et al., 2015). MDSCs can enhance tumor 
cell proliferation, facilitate tumor metastasis and angiogenesis, and promote drug resistance (Draghiciu et al., 2015; Gabrilovich, 2017). Increased numbers of tumor-infiltrating MDSCs often correlate with high tumor burden and metastasis, contributing to poor prognosis (Nagaraj and Gabrilovich, 2008; Malek et al., 2016). To avoid stimulating MDSCs, a dual-functional carrier of PEG linked to NLG919 via an Fmoc moiety was loaded with both PTX and sunitinib (Chen et al., 2018), an FDA-approved tyrosine kinase inhibitor for the treatment of various cancers. Sunitinib reduces the level and activity of MDSCs and Treg cells systemically and in the tumor microenviroment (van Hooren et al., 2016; Motzer et al., 2017). These micelles then deliver three anti-tumor components to the cancer: PTX and sunitinib lead to synergistic killing of tumor cells as well as the induction of antitumor immune responses following the release and presentation of tumor antigens, sunitinib inhibits cytokines needed to recruit MDSCs, and NLG919 is released quite slowly to inhibit IDO and thereby sustain an immune-active tumor microenvironment.

In other studies, the dual-functional carrier of PEG-linked to NLG919 via an Fmoc moiety was loaded with DOX for immunochemotherapy against lymphoma (Zhai et al., 2017). The DOX-loaded micelles were small $(<120 \mathrm{~nm})$, showed sustained drug release, and triggered significantly large numbers of total CD4+/CD8+ T cells and functional CD4+/CD8+ T cells in mice with lymphoma than the same micelles without DOX. These micelles, whether loaded with DOX or not, reduced the recruitment of granulocytic MDSC and monocytic MDSCs to tumor tissues. This contrasts with the observation that the same micelles, when loaded with PTX, triggered the counterproductive accumulation of MDSCs (Chen et al., 2018). These differences may reflect the different abilities of DOX and PTX to modulate the immune system. More studies are needed to better understand the impact of different immunochemotherapies on the tumor microenvironment and overall anti-tumor effects.

\section{PEG-DERIVATIZED DUAL-FUNCTIONAL MICELLES WITH IMPROVED DRUG LOADING CAPACITY}

Dual-functional micelles not only exert intrinsic therapeutic effects, but also deliver other drugs to tumor sites. Most of these micelles load drugs via hydrophobic interaction, hydrogen bonding, and $\pi-\pi$ stacking between the encapsulated drug and the hydrophobic components of the micelle (Lu et al., 2013a; Mohamed et al., 2014). This means that one way to improve drug loading capacity is to increase the density of the hydrophobic component. Conjugating PEG to multiple vitamin E molecules rather than one molecule improved drug loading capacity (Wang et al., 2012), and increasing the number of vitamin E, embelin, or FTS molecules conjugated to one PEG molecule increased drug loading capacity (Lu et al., 2013b; Lu et al., 2014c; Zhang et al., 2014e). We found that conjugating PEG to six vitamin E molecules $\left(\mathrm{PAMV}_{6}\right)$ gave the highest drug loading capacity (Li et al., 2016b). The wheat-like structure of the hydrophobic chains of $\mathrm{PAMV}_{6}$ likely creates a binding pocket that enhances the interaction between carrier and loaded drug. However, increasing the number of conjugated vitamin $\mathrm{E}$ molecules to $10\left(\mathrm{PAMV}_{10}\right)$ gave heterogeneous micelles, presumably because the balance between hydrophilic and hydrophobic chains was destroyed. These results suggest that increasing the density of the hydrophobic component can increase drug loading capacity only to a certain extent.

While the dual-functional micelles discussed so far in this review are effective in formulating drugs that are strongly hydrophobic, they are less effective at formulating moderately hydrophobic drugs. This can be improved by introducing hydrotropic motifs into the hydrohobic domain of polymeric micelles, which improves drug loading capacity and micelle stability (Cho et al., 2004; Huh et al., 2005). In fact, covalent coupling of the moderately hydrophobic DOX into the hydrophobic domain of polymeric micelles improves the loading capacity of free DOX (Yoo and Park, 2004b; Yoo and Park, 2004a).

Another way to improve drug-loading capacity and formulation stability is to incorporate a surfactant at the interface between carrier and drug (Gao et al., 2013). The Fmoc moiety, a functional group routinely used to protect amino acids, is one of the most potent drug-interacting motifs (Table 2). Fmocbased micelles can effectively encapsulate six drugs with diverse structures: probucol, niclosamide, progesterone, cyclosporin A, nifedipine, and griseofulvin (Gao et al., 2013; Zhang et al., 2014b). Hydrophobic interactions and $\pi-\pi$ stacking may contribute to drug-Fmoc interactions. Consistent with this idea, introduction of the Fmoc domain into PEG-derivatized vitamin E (Zhang et al., 2014f; Xu et al., 2017) and FTS carriers (Zhang et al., 2014i; Lu et al., 2015) improves their drug-loading capacity, probably because the Fmoc can engage in stacking interactions with the interfacial aromatic ring of vitamin E and FTS. A PEG-derivatized ibuprofen conjugate $\left(\mathrm{PEG}_{2 \mathrm{~K}}-\mathrm{FIbu}\right)$ consisting of a hydrophilic PEG segment, Fmoc motif, and hydrophobic ibuprofen domain readily formed stable micelles with PTX in the nanosize range $(\sim 100 \mathrm{~nm})$ to a relatively high loading capacity of $67 \%$ (Zhao et al., 2016). In vitro cytotoxicity showed that PTX formulated in $\mathrm{PEG}_{2 \mathrm{~K}}$-FIbu micelles was comparable to Taxol in inhibiting the proliferation of tumor cells. The lack of synergy between the ibuprofen-based carrier and PTX is likely due to the very low concentrations of carriers used in the cytotoxicity study. In vivo, PTX-loaded $\mathrm{PEG}_{2 \mathrm{~K}}$-FIbu micelles showed a much more pronounced therapeutic efficacy compared with Taxol formulation. The improved antitumor activity of PTX-loaded $\mathrm{PEG}_{2 \mathrm{~K}}$-FIbu micelles is likely attributed to the enhanced delivery of PTX to the tumors and the potential synergy between the micellar carrier and PTX.

\section{CHALLENGES AND FUTURE CONSIDERATIONS OF DUAL- FUNCTIONAL MICELLAR CARRIER}

A large number of preclinical studies on dual-functional micelles have been published, which showed great promise to be an 
TABLE 2 | Fmoc-based PEG-derivatized dual-functional micellar systems.

\begin{tabular}{|c|c|c|c|c|c|}
\hline $\begin{array}{l}\text { PEG-derivatized micellar } \\
\text { carriers }\end{array}$ & Hydrophobic segment & Co-loaded drug & $\begin{array}{l}\text { Drug loading } \\
\text { capacity }\end{array}$ & $\begin{array}{l}\text { Drug loading } \\
\text { efficiency }\end{array}$ & References \\
\hline$P E G_{5 K}-F m o c-V E_{2}$ & Vitamin E & Doxorubicin & $39.9 \%$ & $79.5 \%$ & (Lu et al., 2014c) \\
\hline $\mathrm{PEG}_{5 \mathrm{~K}}-(\mathrm{Fmoc}-\mathrm{VE})_{2}$ & Vitamin E & Paclitaxel & $20.8 \%$ & $80.7 \%$ & (Zhang et al., 2014i) \\
\hline $\mathrm{PEG}_{5 \mathrm{~K}}-\mathrm{Fmoc}-\mathrm{VE}_{2}$ & Vitamin $\mathrm{E}$ & Camptothecin & $9.2 \%$ & $70.5 \%$ & (Lu et al., 2015) \\
\hline \multirow[t]{2}{*}{$\mathrm{PEG}_{5 \mathrm{~K}}-\mathrm{Fmoc}^{-\mathrm{FTS}_{2}}$} & \multirow[t]{2}{*}{ S-trans,transfarnesylthiosalicylic acid } & Paclitaxel & $12.1 \%$ & $55.4 \%$ & (Zhang et al., 2014f) \\
\hline & & Doxorubicin & $32.8 \%$ & $69.7 \%$ & \\
\hline $\mathrm{PEG}_{5 \mathrm{~K}}$-Fmoc-S-S-FTS ${ }_{2}$ & S-trans,transfarnesylthiosalicylic acid & Paclitaxel & $34.0 \%$ & $53.5 \%$ & (Xu et al., 2017) \\
\hline PEG-Fmoc-GA & Glycyrrhizic acid & Doxorubicin & $7.3 \%$ & $93.2 \%$ & (Yang et al., 2018b) \\
\hline $\mathrm{PEG}_{2 \mathrm{~K}}-\mathrm{Fmoc}-\mathrm{NLG}$ & NLG919 & Paclitaxel & $24.7 \%$ & - & (Chen et al., 2016) \\
\hline \multirow[t]{2}{*}{$P E G_{2 K}-F m o c-N L G$} & \multirow[t]{2}{*}{ NLG919 } & Paclitaxel & $5.6 \%$ & $98.3 \%$ & \\
\hline & & Sunitinib & $8.0 \%$ & $96.4 \%$ & (Chen et al., 2018) \\
\hline $\mathrm{PEG}_{2 \mathrm{~K}}-\mathrm{Fmoc}-\mathrm{NLG}$ & NLG919 & Doxorubicin & $15.6 \%$ & $93.6 \%$ & (Zhai et al., 2017) \\
\hline $\mathrm{PEG}_{2 \mathrm{~K}}-\mathrm{Fmoc}-\mathrm{lbu}$ & Ibuprofen & Paclitaxel & $67.3 \%$ & $88.4 \%$ & (Zhao et al., 2016) \\
\hline
\end{tabular}

effective nanomedicine platform for drug delivery and cancer therapy. However, the clinical translation and desired therapeutic effects of dual-functional micelles are still far from satisfactory (Cabral and Kataoka, 2014). Micellar system share the limitations inherent to other nanodelivery system which mainly rely on the passive targeting of tumors based on the EPR effect (Fang et al., 2011). Poor tumor penetration due to high interstitial pressure and inefficient tumor cell uptake as well as off target liver and spleen accumulations have been repeatedly reported with the use of micelles (Taurin et al., 2012). The targeting effect in human sometimes is not as pronounced as that obtained in the simple cell or animal models due to the complexity of the human body. To this end, ligand-installed polymeric micelles have the potential for overcoming such biological barriers by taking advantage of receptor-mediated active target mechanisms (Deshayes et al., 2013). The end-group of the PEG segment can be readily modified with ligands capable of recognition of cell-specific surface receptors, providing cellular selectivity and superior intracellular delivery to dual-functional polymeric micelles. The effect of various ligands, including peptides, antibody fragments, and small molecules, installed on nanocarriers, has been confirmed to improve their targeting efficiency (Allen, 2002; Bae et al., 2005). For example, cyclic-RGD (cRGD) peptides have been recognized as specific ligands for integrin $\alpha v \beta 3$ which is overexpressed in neovasculature and tumor cells (Kulhari et al., 2015; Li et al., 2019). cRGD-modified polymeric micelles loaded with DACHPt not only enhanced the cellular uptake of micelles by cancer cells, but also achieved efficient drug delivery in a mouse model of glioblastoma (Miura et al., 2013). Even though glioblastoma is notorious for its poor permeability due to the presence of the blood-brain tumor barrier, these cRGDinstalled micelles rapidly penetrated and accumulated within tumor tissues.

Besides, the premature drug release in the bloodstream and inadequate drug release in the tumor may also account for the inferior therapeutic effects in human patients. Most of toxicities reported in clinical trials resulted from the micelle releasing the drug in the blood, causing toxic side effects similar to the free drug and thereby deviate from tumor targeting (Miller et al., 2013). Ideally, the drug is retained in the polymeric micelles during circulation but is released after accumulation in the tumor interstitium. The design of stimuli-responsive nanomicellar carriers is a very effective way to achieve tumor-targeted drug delivery and adequate release (Zhou et al., 2018a). Numerous stimuli-responsive dual-functional nanomicelles have been developed to deliver anticancer drug in response to a variety of extra/intracellular stimuli or external triggers, including $\mathrm{pH}$, redox potential, enzymes, temperature, light, ultrasound, and magnetic field (Kalhapure and Renukuntla, 2018). It is reported that the microenvironment of most solid tumors is intrinsically acidic ( $\mathrm{pH}$ 6.5-7.2), while the $\mathrm{pH}$ value in the blood and normal tissue is about 7.4. An even lower acidic $\mathrm{pH}$ is found in endosomes and lysosomes (pH 4.5-6.5) (Qu et al., 2017a; Liang et al., 2019). Accordingly, the difference in $\mathrm{pH}$ has been widely exploited to achieve tumor site- or organelle-specific activation of $\mathrm{pH}$-responsive nanomicelles. Yang et al. developed a novel multifunctional $\mathrm{pH}$-sensitive nanomicelle based on luteinizing hormone-releasing hormone (LHRH)-PEG-PHis-DOX/DOXtrans-activating transcriptional activator (TAT) acid-sensitive micelle, which could dissociate and release DOX-TAT when responding to the tumor extracellular $\mathrm{pH}$ (Yang et al., 2015). Such systems could efficiently go across the cell membrane and reach the cytosol of the multidrug-resistant cancer cells, resulting in the remarkable antitumor efficacy and negligible systematic toxicity.

In addition, PEG is believed to provide a steric barrier around the nanocarriers, and thus prolonging their blood circulation time. However, there was an unexpected pharmacokinetic alteration brought about with a second dose of PEGylated nanoparticles, the so-called accelerated blood clearance (ABC) phenomenon (Ishida and Kiwada, 2008). With this phenomenon, a second dose of PEG-derivatized nanomicelles, PEGylated liposomes, or PEGcontaining microemulsions is rapidly cleared from circulation when administered within a certain time interval from injection of the first dose due to an enhanced accumulation in the liver (Abu Lila et al., 2013). Many attempts have focused on the use of other polymers, such as chitosan and hyaluronic acid, to replace PEG modification and to avoid the occurrence of the $\mathrm{ABC}$ phenomenon (Dong et al., 2016). Moreover, polyetherimide-based dual-functional carrier is an alternative strategy for the delivery of charged macromolecules, such as antisense oligonucleotides, plasmid DNA, and siRNA/ 
miRNA (Zhou et al., 2018b). David Oupicky's group developed many polycationic CXCR4 antagonist based dual-functional nanomicellar carriers that can simultaneously deliver siRNA and inhibit CXCR4 to achieve combination anticancer therapy (Li et al., 2012; Zhou et al., 2018b). Such dual-function delivery vectors could enhance antimetastatic efficacy of a variety of cancer gene therapy methods (Li and Oupicky, 2014; Sun et al., 2018a).

\section{CONCLUSIONS}

Dual-functional nanomicelles have emerged as a versatile and powerful platform for cancer therapy. They can self-assemble and efficiently encapsulate chemotherapeutic agents such as PTX and DOX into their hydrophobic core. They exert anti-tumor effects by virtue of the encapsulated drug as well as the intrinsic anticancer activity of carrier materials in the micelles. As a result, these micelle systems can enhance the efficacy of anti-tumor drugs while reducing their systemic toxicity; in fact, the carrier materials and drug cargo can synergize to increase efficacy.

\section{REFERENCES}

Abu Lila, A. S., Kiwada, H., and Ishida, T. (2013). The accelerated blood clearance (ABC) phenomenon: clinical challenge and approaches to manage. J. Control. Release 172, 38-47. doi: 10.1016/j.jconrel.2013.07.026

Allen, T. M. (2002). Ligand-targeted therapeutics in anticancer therapy. Nat. Rev. Cancer 2, 750-763. doi: 10.1038/nrc903

Bae, Y., Jang, W. D., Nishiyama, N., Fukushima, S., and Kataoka, K. (2005). Multifunctional polymeric micelles with folate-mediated cancer cell targeting and $\mathrm{pH}$-triggered drug releasing properties for active intracellular drug delivery. Mol. Biosyst. 1, 242-250. doi: 10.1039/b500266d

Bae, Y., and Kataoka, K. (2009). Intelligent polymeric micelles from functional poly(ethylene glycol)-poly(amino acid) block copolymers. Adv. Drug Deliv. Rev. 61, 768-784. doi: 10.1016/j.addr.2009.04.016

Biswas, S., Kumari, P., Lakhani, P. M., and Ghosh, B. (2016). Recent advances in polymeric micelles for anti-cancer drug delivery. Eur. J. Pharm. Sci. 83, 184202. doi: 10.1016/j.ejps.2015.12.031

Blair, H. A., and Deeks, E. D. (2015). Albumin-bound Paclitaxel: a review in nonsmall cell lung cancer. Drugs 75, 2017-2024. doi: 10.1007/s40265-015-0484-9

Botella, P., and Rivero-Buceta, E. (2017). Safe approaches for camptothecin delivery: structural analogues and nanomedicines. J. Control. Release 247, 28-54. doi: 10.1016/j.jconrel.2016.12.023

Bourgeois-Daigneault, M. C., St-Germain, L. E., Roy, D. G., Pelin, A., Aitken, A. S., Arulanandam, R., et al. (2016). Combination of Paclitaxel and MG1 oncolytic virus as a successful strategy for breast cancer treatment. Breast Cancer Res 18, 83. doi: 10.1186/s13058-016-0744-y

Bracci, L., Schiavoni, G., Sistigu, A., and Belardelli, F. (2014). Immune-based mechanisms of cytotoxic chemotherapy: implications for the design of novel and rationale-based combined treatments against cancer. Cell Death Differ. 21, 15-25. doi: 10.1038/cdd.2013.67

Cabral, H., and Kataoka, K. (2014). Progress of drug-loaded polymeric micelles into clinical studies. J. Control. Release 190, 465-476. doi: 10.1016/j.jconrel. 2014.06.042

Cagel, M., Tesan, F. C., Bernabeu, E., Salgueiro, M. J., Zubillaga, M. B., Moretton, M. A., et al. (2017). Polymeric mixed micelles as nanomedicines: achievements and perspectives. Eur. J. Pharm. Biopharm. 113, 211-228. doi: 10.1016/j. ejpb.2016.12.019

Chabner, B. A., and Roberts, T. G., Jr. (2005). Chemotherapy and the war on cancer. Nat. Rev. Cancer 5, 65. doi: 10.1038/nrc1529

Chakrawarti, L., Agrawal, R., Dang, S., Gupta, S., and Gabrani, R. (2016). Therapeutic effects of EGCG: a patent review. Expert Opin. Ther. Pat. 26, 907916. doi: 10.1080/13543776.2016.1203419
Most of these dual-functional micelles rely on passive targeting, so more effective strategies are needed to enhance their targeted delivery, deepen their penetration into the tumor, and enable drug release in response to specific stimuli. Much work remains to be done to translate these promising nanomaterials into the clinic, including scale-up for industrial production and validation studies in appropriate animal models.

\section{AUTHOR CONTRIBUTIONS}

$\mathrm{YL}$ and $\mathrm{JH}$ wrote the manuscript and obtained funding, $\mathrm{TZ}$ and QL contributed to the discussion and review of the manuscript.

\section{FUNDING}

This work was financially supported by the National Natural Science Foundation of China (81603035 and 81870599), China Postdoctoral Fellowship (2017M612981 and 2018T110986).

Cheng, Y., and Ji, Y. (2019). RGD-modified polymer and liposome nanovehicles: recent research progress for drug delivery in cancer therapeutics. Eur. J. Pharm. Sci. 128, 8-17. doi: 10.1016/j.ejps.2018.11.023

Chen, Y., Sun, J., Huang, Y., Lu, B., and Li, S. (2018). Improved cancer immunochemotherapy via optimal co-delivery of chemotherapeutic and immunomodulatory agents. Mol. Pharm. 15, 5162-5173. doi: 10.1021/acs. molpharmaceut.8b00717

Chen, Y., Xia, R., Huang, Y., Zhao, W., Li, J., Zhang, X., et al. (2016). An immunostimulatory dual-functional nanocarrier that improves cancer immunochemotherapy. Nat. Commun. 7, 13443. doi: 10.1038/ncomms13443

Chen, Y., Zhang, X., Lu, J., Huang, Y., Li, J., and Li, S. (2014). Targeted delivery of curcumin to tumors via PEG-derivatized FTS-based micellar system. AAPS J. 16, 600-608. doi: 10.1208/s12248-014-9595-6

Cheng, T., Liu, J., Ren, J., Huang, F., Ou, H., Ding, Y., et al. (2016). Green tea catechin-based complex micelles combined with doxorubicin to overcome cardiotoxicity and multidrug resistance. Theranostics 6, 1277-1292. doi: 10.7150/ thno. 15133

Chitra, M., Sukumar, E., Suja, V., and Devi, C. S. (1994). Antitumor, antiinflammatory and analgesic property of embelin, a plant product. Chemotherapy 40, 109-113. doi: 10.1159/000239181

Cho, Y. W., Lee, J., Lee, S. C., Huh, K. M., and Park, K. (2004). Hydrotropic agents for study of in vitro paclitaxel release from polymeric micelles. J. Control. Release 97, 249-257. doi: 10.1016/j.jconrel.2004.03.013

Chung, J. E., Tan, S., Gao, S. J., Yongvongsoontorn, N., Kim, S. H., Lee, J. H., et al. (2014). Self-assembled micellar nanocomplexes comprising green tea catechin derivatives and protein drugs for cancer therapy. Nat. Nanotechnol. 9, 907-912. doi: 10.1038/nnano.2014.208

Collnot, E. M., Baldes, C., Schaefer, U. F., Edgar, K. J., Wempe, M. F., and Lehr, C. M. (2010). Vitamin E TPGS P-glycoprotein inhibition mechanism: influence on conformational flexibility, intracellular ATP levels, and role of time and site of access. Mol. Pharm. 7, 642-651. doi: 10.1021/mp900191s

Constantinides, P. P., Han, J., and Davis, S. S. (2006). Advances in the use of tocols as drug delivery vehicles. Pharm. Res. 23, 243-255. doi: 10.1007/ s11095-005-9262-9

Curran, M. A., Montalvo, W., Yagita, H., and Allison, J. P. (2010). PD-1 and CTLA-4 combination blockade expands infiltrating $\mathrm{T}$ cells and reduces regulatory $\mathrm{T}$ and myeloid cells within B16 melanoma tumors. Proc. Natl. Acad. Sci. U.S.A. 107, 4275-4280. doi: 10.1073/pnas.0915174107

Deshayes, S., Cabral, H., Ishii, T., Miura, Y., Kobayashi, S., Yamashita, T., et al. (2013). Phenylboronic acid-installed polymeric micelles for targeting sialylated epitopes in solid tumors. J. Am. Chem. Soc. 135, 15501-15507. doi: 10.1021/ ja406406h 
Deshmukh, A. S., Chauhan, P. N., Noolvi, M. N., Chaturvedi, K., Ganguly, K., Shukla, S. S., et al. (2017). Polymeric micelles: basic research to clinical practice. Int. J. Pharm. 532, 249-268. doi: 10.1016/j.ijpharm.2017.09.005

Dong, H., Dong, C., Yue, F., Ren, T., Zhang, Z., Lan, L., et al. (2012). Engineering of peglayted camptothecin into core-shell nanomicelles for improving solubility, stability and combination delivery. MedChemComm 3, 1555. doi: 10.1039/ c2md20153d

Dong, L. F., Low, P., Dyason, J. C., Wang, X. F., Prochazka, L., Witting, P. K., et al. (2008). Alpha-tocopheryl succinate induces apoptosis by targeting ubiquinone-binding sites in mitochondrial respiratory complex II. Oncogene 27, 4324-4335. doi: 10.1038/onc.2008.69

Dong, L. F., Swettenham, E., Eliasson, J., Wang, X. F., Gold, M., Medunic, Y., et al. (2007). Vitamin $E$ analogues inhibit angiogenesis by selective induction of apoptosis in proliferating endothelial cells: the role of oxidative stress. Cancer Res. 67, 11906-11913. doi: 10.1158/0008-5472.CAN-07-3034

Dong, R., Zhao, X., Guo, B., and Ma, P. X. (2016). Self-healing conductive injectable hydrogels with antibacterial activity as cell delivery carrier for cardiac cell therapy. ACS Appl. Mater. Interfaces 8, 17138-17150. doi: 10.1021/ acsami.6b04911

Draghiciu, O., Lubbers, J., Nijman, H. W., and Daemen, T. (2015). Myeloid derived suppressor cells-an overview of combat strategies to increase immunotherapy efficacy. Oncoimmunology 4, e954829. doi: 10.4161/21624011.2014.954829

Duncan, R. (2014). Polymer therapeutics: top 10 selling pharmaceuticals - what next? J. Control. Release 190, 371-380. doi: 10.1016/j.jconrel.2014.05.001

Erlich, S., Tal-Or, P., Liebling, R., Blum, R., Karunagaran, D., Kloog, Y., et al. (2006). Ras inhibition results in growth arrest and death of androgen-dependent and androgen-independent prostate cancer cells. Biochem. Pharmacol. 72, 427-436. doi: 10.1016/j.bcp.2006.05.007

Fang, J., Nakamura, H., and Maeda, H. (2011). The EPR effect: unique features of tumor blood vessels for drug delivery, factors involved, and limitations and augmentation of the effect. Adv. Drug Deliv. Rev. 63, 136-151. doi: 10.1016/j. addr.2010.04.009

Farabegoli, F., Barbi, C., Lambertini, E., and Piva, R. (2007). (-)-Epigallocatechin3-gallate downregulates estrogen receptor alpha function in MCF-7 breast carcinoma cells. Cancer Detect. Prev. 31, 499-504. doi: 10.1016/j. cdp.2007.10.018

Gabrilovich, D. I. (2017). Myeloid-derived suppressor cells. Cancer Immunol. Res. 5, 3-8. doi: 10.1158/2326-6066.CIR-16-0297

Gana-Weisz, M., Halaschek-Wiener, J., Jansen, B., Elad, G., Haklai, R., and Kloog, Y. (2002). The Ras inhibitor S-trans, trans-farnesylthiosalicylic acid chemosensitizes human tumor cells without causing resistance. Clin. Cancer Res. 8, 555-565. doi: 10.1093/carcin/23.2.373-A

Gao, X., Huang, Y., Makhov, A. M., Epperly, M., Lu, J., Grab, S., et al. (2013). Nanoassembly of surfactants with interfacial drug-interactive motifs as tailordesigned drug carriers. Mol. Pharm. 10, 187-198. doi: 10.1021/mp300319m

Gao, Y., Xiao, Y., Liu, S., and Yu, J. (2018). Camptothecin prodrug nanomicelle based on a boronate ester-linked diblock copolymer as the carrier of doxorubicin with enhanced cellular uptake. J. Biomater. Sci. Polym. Ed. 29, 160-180. doi: 10.1080/09205063.2017.1406632

Geszke-Moritz, M., and Moritz, M. (2016). Solid lipid nanoparticles as attractive drug vehicles: composition, properties and therapeutic strategies. Mater. Sci. Eng. C Mater. Biol. Appl. 68, 982-994. doi: 10.1016/j.msec.2016.05.119

Gong, J., Chen, M., Zheng, Y., Wang, S., and Wang, Y. (2012). Polymeric micelles drug delivery system in oncology. J. Control. Release 159, 312-323. doi: 10.1016/j.jconrel.2011.12.012

Gothwal, A., Khan, I., and Gupta, U. (2016). Polymeric micelles: recent advancements in the delivery of anticancer drugs. Pharm. Res. 33, 18-39. doi: 10.1007/s11095-015-1784-1

Greco, F., and Vicent, M. J. (2008). Polymer-drug conjugates: current status and future trends. Front. Biosci. 13, 2744-2756. doi: 10.2741/2882

Greenwald, R. B., Gilbert, C. W., Pendri, A., Conover, C. D., Xia, J., and Martinez, A. (1996). Drug delivery systems: water soluble taxol 2'-poly(ethylene glycol) ester prodrugs-design and in vivo effectiveness. J. Med. Chem. 39, 424-431. doi: $10.1021 / \mathrm{jm} 950475 \mathrm{e}$

Gromova, Ii, Buchman, V. L., Abagyan, R. A., Ulyanov, A. V., and Bronstein, I. B. (1990). Sequence dependent modulating effect of camptothecin on the DNAcleaving activity of the calf thymus type I topoisomerase. Nucleic Acids Res. 18, 637-645. doi: 10.1093/nar/18.3.637
Groth, C., Hu, X., Weber, R., Fleming, V., Altevogt, P., Utikal, J., et al. (2019). Immunosuppression mediated by myeloid-derived suppressor cells (MDSCs) during tumour progression. Br. J. Cancer 120, 16-25. doi: 10.1038/s41416-0180333-1

Guo, Y., Luo, J., Tan, S., Otieno, B. O., and Zhang, Z. (2013). The applications of vitamin E TPGS in drug delivery. Eur. J. Pharm. Sci. 49, 175-186. doi: 10.1016/j. ejps.2013.02.006

Heo, J. Y., Kim, H. J., Kim, S. M., Park, K. R., Park, S. Y., Kim, S. W., et al. (2011). Embelin suppresses STAT3 signaling, proliferation, and survival of multiple myeloma via the protein tyrosine phosphatase PTEN. Cancer Lett. 308, 71-80. doi: 10.1016/j.canlet.2011.04.015

Hoste, K., De Winne, K., and Schacht, E. (2004). Polymeric prodrugs. Int. J. Pharm. 277, 119-131. doi: 10.1016/j.ijpharm.2003.07.016

Huang, D., Zhuang, Y., Shen, H., Yang, F., Wang, X., and Wu, D. (2018). Acetallinked PEGylated paclitaxel prodrugs forming free-paclitaxel-loaded pH-responsive micelles with high drug loading capacity and improved drug delivery. Mater. Sci. Eng. C Mater. Biol. Appl. 82, 60-68. doi: 10.1016/j. msec.2017.08.063

Huang, Y., Lu, J., Gao, X., Li, J., Zhao, W., Sun, M., et al. (2012). PEG-derivatized embelin as a dual functional carrier for the delivery of paclitaxel. Bioconjug. Chem. 23, 1443-1451. doi: 10.1021/bc3000468

Huh, K. M., Lee, S. C., Cho, Y. W., Lee, J., Jeong, J. H., and Park, K. (2005). Hydrotropic polymer micelle system for delivery of paclitaxel. J. Control. Release 101, 59-68. doi: 10.1016/j.jconrel.2004.07.003

Hussain, A. R., Siraj, A. K., Ahmed, M., Bu, R., Pratheeshkumar, P., Alrashed, A. M., et al. (2017). XIAP over-expression is an independent poor prognostic marker in Middle Eastern breast cancer and can be targeted to induce efficient apoptosis. BMC Cancer 17, 640. doi: 10.1186/s12885-017-3627-4

Ishida, T., and Kiwada, H. (2008). Accelerated blood clearance (ABC) phenomenon upon repeated injection of PEGylated liposomes. Int. J. Pharm. 354, 56-62. doi: 10.1016/j.ijpharm.2007.11.005

Jiang, X., Wang, J., Deng, X., Xiong, F., Ge, J., Xiang, B., et al. (2019). Role of the tumor microenvironment in PD-L1/PD-1-mediated tumor immune escape. Mol. Cancer 18, 10. doi: 10.1186/s12943-018-0928-4

Jin, X., Song, L., Liu, X., Chen, M., Li, Z., Cheng, L., et al. (2014). Protective efficacy of vitamins $\mathrm{C}$ and $\mathrm{E}$ on $\mathrm{p}, \mathrm{p}$-DDT-induced cytotoxicity via the ROS-mediated mitochondrial pathway and NF-kappaB/FasL pathway. PLoS One 9, e113257. doi: 10.1371/journal.pone.0113257

Jodoin, J., Demeule, M., and Beliveau, R. (2002). Inhibition of the multidrug resistance P-glycoprotein activity by green tea polyphenols. Biochim. Biophys. Acta 1542, 149-159. doi: 10.1016/S0167-4889(01)00175-6

Kalhapure, R. S., and Renukuntla, J. (2018). Thermo- and pH dual responsive polymeric micelles and nanoparticles. Chem. Biol. Interact. 295, 20-37. doi: 10.1016/j.cbi.2018.07.016

Kanai, K., Kikuchi, E., Mikami, S., Suzuki, E., Uchida, Y., Kodaira, K., et al. (2010). Vitamin E succinate induced apoptosis and enhanced chemosensitivity to paclitaxel in human bladder cancer cells in vitro and in vivo. Cancer Sci. 101, 216-223. doi: 10.1111/j.1349-7006.2009.01362.x

Kedar, U., Phutane, P., Shidhaye, S., and Kadam, V. (2010). Advances in polymeric micelles for drug delivery and tumor targeting. Nanomedicine 6, 714-729. doi: 10.1016/j.nano.2010.05.005

Kim, S. W., Kim, S. M., Bae, H., Nam, D., Lee, J. H., Lee, S. G., et al. (2013). Embelin inhibits growth and induces apoptosis through the suppression of Akt/mTOR/ S6K1 signaling cascades. Prostate 73, 296-305. doi: 10.1002/pros.22574

Kline, K., Yu, W., and Sanders, B. G. (2004). Vitamin E and breast cancer. J. Nutr. 134, 3458s-3462s. doi: 10.1093/jn/134.12.3458S

Kloog, Y., and Cox, A. D. (2000). RAS inhibitors: potential for cancer therapeutics. Mol. Med. Today 6, 398-402. doi: 10.1016/S1357-4310(00)01789-5

Ko, J. H., Lee, S. G., Yang, W. M., Um, J. Y., Sethi, G., Mishra, S., et al. (2018). The application of embelin for cancer prevention and therapy. Molecules 23, E621. doi: 10.3390/molecules 23030621

Koo, O. M., Rubinstein, I., and Onyuksel, H. (2005). Camptothecin in sterically stabilized phospholipid micelles: a novel nanomedicine. Nanomedicine 1, 77-84. doi: 10.1016/j.nano.2004.11.002

Kulhari, H., Pooja, D., Shrivastava, S., Telukutala, S. R., Barui, A. K., Patra, C. R., et al. (2015). Cyclic-RGDfK peptide conjugated succinoyl-TPGS nanomicelles for targeted delivery of docetaxel to integrin receptor over-expressing angiogenic tumours. Nanomedicine 11, 1511-1520. doi: 10.1016/j.nano.2015.04.007 
Kumar, A., Sirohi, V. K., Anum, F., Singh, P. K., Gupta, K., Gupta, D., et al. (2017). Enhanced apoptosis, survivin down-regulation and assisted immunochemotherapy by curcumin loaded amphiphilic mixed micelles for subjugating endometrial cancer. Nanomedicine 13, 1953-1963. doi: 10.1016/j.nano.2017.04.014

Laheru, D., Shah, P., Rajeshkumar, N. V., Mcallister, F., Taylor, G., Goldsweig, H., et al. (2012). Integrated preclinical and clinical development of S-trans, transFarnesylthiosalicylic Acid (FTS, Salirasib) in pancreatic cancer. Invest. New Drugs 30, 2391-2399. doi: 10.1007/s10637-012-9818-6

Le, C. T., Leenders, W. P. J., Molenaar, R. J., and Van Noorden, C. J. F. (2018). Effects of the green tea polyphenol epigallocatechin-3-gallate on glioma: a critical evaluation of the literature. Nutr. Cancer 70, 317-333. doi: 10.1080/01635581.2018.1446090

Li, J., Li, Y., Wang, Y., Ke, W., Chen, W., Wang, W., et al. (2017). Polymer prodrugbased nanoreactors activated by tumor acidity for orchestrated oxidation/ chemotherapy. Nano Lett. 17, 6983-6990. doi: 10.1021/acs.nanolett.7b03531

Li, J., and Oupicky, D. (2014). Effect of biodegradability on CXCR4 antagonism, transfection efficacy and antimetastatic activity of polymeric Plerixafor. Biomaterials 35, 5572-5579. doi: 10.1016/j.biomaterials.2014.03.047

Li, J., Zhu, Y., Hazeldine, S. T., Li, C., and Oupicky, D. (2012). Dual-function CXCR4 antagonist polyplexes to deliver gene therapy and inhibit cancer cell invasion. Angew. Chem. Int. Ed. Engl. 51, 8740-8743. doi: 10.1002/anie.201203463

Li, M., Bolduc, A. R., Hoda, M. N., Gamble, D. N., Dolisca, S. B., Bolduc, A. K., et al. (2014). The indoleamine 2,3-dioxygenase pathway controls complementdependent enhancement of chemo-radiation therapy against murine glioblastoma. J. Immunother. Cancer 2, 21. doi: 10.1186/2051-1426-2-21

Li, X. Q., Wen, H. Y., Dong, H. Q., Xue, W. M., Pauletti, G. M., Cai, X. J., et al. (2011). Self-assembling nanomicelles of a novel camptothecin prodrug engineered with a redox-responsive release mechanism. Chem. Commun. (Camb.) 47, 8647-8649. doi: 10.1039/c1cc12495a

Li, Y., Li, R., Liu, Q., Li, W., Zhang, T., Zou, M., et al. (2016a). One-step selfassembling nanomicelles for pirarubicin delivery to overcome multidrug resistance in breast cancer. Mol. Pharm. 13, 3934-3944. doi: 10.1021/acs. molpharmaceut.6b00712

Li, Y., Liu, Q., Li, W., Zhang, T., Li, H., Li, R., et al. (2016b). Design and validation of PEG-derivatized vitamin E copolymer for drug delivery into breast cancer. Bioconjug. Chem. 27, 1889-1899. doi: 10.1021/acs.bioconjchem.6b00292

Li, Y., Pu, S., Liu, Q., Li, R., Zhang, J., Wu, T., et al. (2019). An integrin-based nanoparticle that targets activated hepatic stellate cells and alleviates liver fibrosis. J. Control. Release 303, 77-90. doi: 10.1016/j.jconrel.2019.04.022

Liang, G., Tang, A., Lin, X., Li, L., Zhang, S., Huang, Z., et al. (2010). Green tea catechins augment the antitumor activity of doxorubicin in an in vivo mouse model for chemoresistant liver cancer. Int. J. Oncol. 37, 111-123. doi: 10.3892/ ijo_00000659

Liang, L., Lin, S. W., Dai, W., Lu, J. K., Yang, T. Y., Xiang, Y., et al. (2012). Novel cathepsin B-sensitive paclitaxel conjugate: higher water solubility, better efficacy and lower toxicity. J. Control. Release 160, 618-629. doi: 10.1016/j.jconrel.2012.02.020

Liang, Y., Zhao, X., Ma, P. X., Guo, B., Du, Y., and Han, X. (2019). pH-responsive injectable hydrogels with mucosal adhesiveness based on chitosan-grafteddihydrocaffeic acid and oxidized pullulan for localized drug delivery. J. Colloid Interface Sci. 536, 224-234. doi: 10.1016/j.jcis.2018.10.056

Liu, J., Zahedi, P., Zeng, F., and Allen, C. (2008). Nano-sized assemblies of a PEGdocetaxel conjugate as a formulation strategy for docetaxel. J. Pharm. Sci. 97, 3274-3290. doi: 10.1002/jps.21245

Liu, X., Shin, N., Koblish, H. K., Yang, G., Wang, Q., Wang, K., et al. (2010). Selective inhibition of IDO1 effectively regulates mediators of antitumor immunity. Blood 115, 3520-3530. doi: 10.1182/blood-2009-09-246124

Lu, J., Chuan, X., Zhang, H., Dai, W., Wang, X., Wang, X., et al. (2014a). Free paclitaxel loaded PEGylated-paclitaxel nanoparticles: preparation and comparison with other paclitaxel systems in vitro and in vivo. Int. J. Pharm. 471, 525-535. doi: 10.1016/j.ijpharm.2014.05.032

Lu, J., Huang, Y., Zhao, W., Chen, Y., Li, J., Gao, X., et al. (2013a). Design and characterization of PEG-derivatized vitamin $\mathrm{E}$ as a nanomicellar formulation for delivery of paclitaxel. Mol. Pharm. 10, 2880-2890. doi: 10.1021/mp300729y

Lu, J., Huang, Y., Zhao, W., Marquez, R. T., Meng, X., Li, J., et al. (2013b). PEGderivatized embelin as a nanomicellar carrier for delivery of paclitaxel to breast and prostate cancers. Biomaterials 34, 1591-1600. doi: 10.1016/j. biomaterials.2012.10.073
Lu, J., Liu, C., Wang, P., Ghazwani, M., Xu, J., Huang, Y., et al. (2015). The self-assembling camptothecin-tocopherol prodrug: an effective approach for formulating camptothecin. Biomaterials 62, 176-187. doi: 10.1016/j. biomaterials.2015.05.046

Lu, J., Zhao, W., Huang, Y., Liu, H., Marquez, R., Gibbs, R. B., et al. (2014b). Targeted delivery of doxorubicin by folic acid-decorated dual functional nanocarrier. Mol. Pharm. 11, 4164-4178. doi: 10.1021/mp500389v

Lu, J., Zhao, W., Liu, H., Marquez, R., Huang, Y., Zhang, Y., et al. (2014c). An improved D-alpha-tocopherol-based nanocarrier for targeted delivery of doxorubicin with reversal of multidrug resistance. J. Control. Release 196, 272286. doi: 10.1016/j.jconrel.2014.10.016

Maeda, H., Bharate, G. Y., and Daruwalla, J. (2009). Polymeric drugs for efficient tumor-targeted drug delivery based on EPR-effect. Eur. J. Pharm. Biopharm. 71, 409-419. doi: 10.1016/j.ejpb.2008.11.010

Maeda, H., Nakamura, H., and Fang, J. (2013). The EPR effect for macromolecular drug delivery to solid tumors: improvement of tumor uptake, lowering of systemic toxicity, and distinct tumor imaging in vivo. Adv. Drug Deliv. Rev. 65, 71-79. doi: 10.1016/j.addr.2012.10.002

Malafa, M. P., Fokum, F. D., Mowlavi, A., Abusief, M., and King, M. (2002). Vitamin E inhibits melanoma growth in mice. Surgery 131, 85-91. doi: 10.1067/ msy.2002.119191

Malafa, M. P., and Neitzel, L. T. (2000). Vitamin E succinate promotes breast cancer tumor dormancy. J. Surg. Res. 93, 163-170. doi: 10.1006/jsre.2000.5948

Malek, E., De Lima, M., Letterio, J. J., Kim, B. G., Finke, J. H., Driscoll, J. J., et al. (2016). Myeloid-derived suppressor cells: the green light for myeloma immune escape. Blood Rev. 30, 341-348. doi: 10.1016/j.blre.2016.04.002

Mautino, M. R., Jaipuri, F. A., Waldo, J., Kumar, S., and Link, C. J. (2013). Abstract 491: NLG919, a novel indoleamine-2,3-dioxygenase (IDO)-pathway inhibitor drug candidate for cancer therapy. Cancer Res. 73, 491-491. doi: 10.1158/15387445.AM2013-491

Mcmahon, L. P., Yue, W., Santen, R. J., and Lawrence, J. C., Jr. (2005) Farnesylthiosalicylic acid inhibits mammalian target of rapamycin (mTOR) activity both in cells and in vitro by promoting dissociation of the mTORraptor complex. Mol. Endocrinol. 19, 175-183. doi: 10.1210/me.2004-0305

Mei, Y., Qian, F., Wei, D., and Liu, J. (2004). Reversal of cancer multidrug resistance by green tea polyphenols. J. Pharm. Pharmacol. 56, 1307-1314. doi: $10.1211 / 0022357044364$

Meirow, Y., Kanterman, J., and Baniyash, M. (2015). Paving the road to tumor development and spreading: myeloid-derived suppressor cells are ruling the fate. Front. Immunol. 6, 523. doi: 10.3389/fimmu.2015.00523

Meng, X., Du, G., Ye, L., Sun, S., Liu, Q., Wang, H., et al. (2017). Combinatorial antitumor effects of indoleamine 2,3-dioxygenase inhibitor NLG919 and paclitaxel in a murine B16-F10 melanoma model. Int. J. Immunopathol. Pharmacol. 30, 215-226. doi: 10.1177/0394632017714696

Mi, Y., Liu, Y., and Feng, S. S. (2011). Formulation of docetaxel by folic acidconjugated d-alpha-tocopheryl polyethylene glycol succinate 2000 (Vitamin E TPGS(2k)) micelles for targeted and synergistic chemotherapy. Biomaterials 32, 4058-4066. doi: 10.1016/j.biomaterials.2011.02.022

Miller, T., Breyer, S., Van Colen, G., Mier, W., Haberkorn, U., Geissler, S., et al. (2013). Premature drug release of polymeric micelles and its effects on tumor targeting. Int. J. Pharm. 445, 117-124. doi: 10.1016/j.ijpharm.2013.01.059

Miura, Y., Takenaka, T., Toh, K., Wu, S., Nishihara, H., Kano, M. R., et al. (2013). Cyclic RGD-linked polymeric micelles for targeted delivery of platinum anticancer drugs to glioblastoma through the blood-brain tumor barrier. ACS Nano 7, 8583-8592. doi: 10.1021/nn402662d

Mohamed, S., Parayath, N. N., Taurin, S., and Greish, K. (2014). Polymeric nanomicelles: versatile platform for targeted delivery in cancer. Ther. Deliv. 5, 11011121. doi: 10.4155/tde.14.69

Molineux, G. (2002). Pegylation: engineering improved pharmaceuticals for enhanced therapy. Cancer Treat. Rev. 28 Suppl A, 13-16. doi: 10.1016/ S0305-7372(02)80004-4

Motzer, R. J., Escudier, B., Gannon, A., and Figlin, R. A. (2017). Sunitinib: ten years of successful clinical use and study in advanced renal cell carcinoma. Oncologist 22, 41-52. doi: 10.1634/theoncologist.2016-0197

Nagaraj, S., and Gabrilovich, D. I. (2008). Tumor escape mechanism governed by myeloid-derived suppressor cells. Cancer Res. 68, 2561-2563. doi: 10.1158/0008-5472.CAN-07-6229 
Naik, S. R., Niture, N. T., Ansari, A. A., and Shah, P. D. (2013). Anti-diabetic activity of embelin: involvement of cellular inflammatory mediators, oxidative stress and other biomarkers. Phytomedicine 20, 797-804. doi: 10.1016/j. phymed.2013.03.003

Nehate, C., Jain, S., Saneja, A., Khare, V., Alam, N., Dubey, R. D., et al. (2014). Paclitaxel formulations: challenges and novel delivery options. Curr. Drug Deliv. 11, 666-686. doi: 10.2174/1567201811666140609154949

Nikolovska-Coleska, Z., Xu, L., Hu, Z., Tomita, Y., Li, P., Roller, P. P., et al. (2004). Discovery of embelin as a cell-permeable, small-molecular weight inhibitor of XIAP through structure-based computational screening of a traditional herbal medicine three-dimensional structure database. J. Med. Chem. 47, 2430-2440. doi: $10.1021 / \mathrm{jm} 030420+$

Pastaki Khoshbin, A., Eskian, M., Keshavarz-Fathi, M., and Rezaei, N. (2019). Roles of myeloid-derived suppressor cells in cancer metastasis: immunosuppression and beyond. Arch. Immunol. Ther. Exp. (Warsz.) 67, 89-102. doi: 10.1007/ s00005-018-0531-9

Peng, M., Huang, B., Zhang, Q., Fu, S., Wang, D., Cheng, X., et al. (2014). Embelin inhibits pancreatic cancer progression by directly inducing cancer cell apoptosis and indirectly restricting IL-6 associated inflammatory and immune suppressive cells. Cancer Lett. 354, 407-416. doi: 10.1016/j.canlet.2014.08.011

Pizzolato, J. F., and Saltz, L. B. (2003). The camptothecins. Lancet 361, 2235-2242. doi: 10.1016/S0140-6736(03)13780-4

Qu, J., Zhao, X., Liang, Y., Zhang, T., Ma, P. X., and Guo, B. (2018). Antibacterial adhesive injectable hydrogels with rapid self-healing, extensibility and compressibility as wound dressing for joints skin wound healing. Biomaterials 183, 185-199. doi: 10.1016/j.biomaterials.2018.08.044

Qu, J., Zhao, X., Ma, P. X., and Guo, B. (2017a).pH-responsive self-healing injectable hydrogel based on N-carboxyethyl chitosan for hepatocellular carcinoma therapy. Acta Biomater. 58, 168-180. doi: 10.1016/j.actbio.2017.06.001

Qu, Y., Chu, B., Shi, K., Peng, J., and Qian, Z. (2017b). Recent progress in functional micellar carriers with intrinsic therapeutic activities for anticancer drug delivery. J. Biomed. Nanotechnol. 13, 1598-1618. doi: 10.1166/jbn.2017.2475

Ray, S., Li, Z., Hsu, C. H., Hwang, L. P., Lin, Y. C., Chou, P. T., et al. (2018). Dendrimer- and copolymer-based nanoparticles for magnetic resonance cancer theranostics. Theranostics 8, 6322-6349. doi: 10.7150/thno.27828

Ricciuti, B., Leonardi, G. C., Puccetti, P., Fallarino, F., Bianconi, V., Sahebkar, A., et al. (2019). Targeting indoleamine-2,3-dioxygenase in cancer: scientific rationale and clinical evidence. Pharmacol. Ther. 196, 105-116. doi: 10.1016/j. pharmthera.2018.12.004

Riely, G. J., Johnson, M. L., Medina, C., Rizvi, N. A., Miller, V. A., Kris, M. G., et al. (2011). A phase II trial of Salirasib in patients with lung adenocarcinomas with KRAS mutations. J. Thorac. Oncol. 6, 1435-1437. doi: 10.1097/JTO. 0b013e318223c099

Ringsdorf, H. (2010). Structure and properties of pharmacologically active polymers. J. Polym. Sci. Polym. Symp. 51, 135-153. doi: 10.1002/polc.5070510111

Safari, E., Ghorghanlu, S., Ahmadi-Khiavi, H., Mehranfar, S., Rezaei, R., and Motallebnezhad, M. (2019). Myeloid-derived suppressor cells and tumor: current knowledge and future perspectives. J. Cell. Physiol. 234, 9966-9981. doi: $10.1002 /$ jcp. 27923

Saito, G., Swanson, J. A., and Lee, K. D. (2003). Drug delivery strategy utilizing conjugation via reversible disulfide linkages: role and site of cellular reducing activities. Adv. Drug Deliv. Rev. 55, 199-215. doi: 10.1016/ S0169-409X(02)00179-5

Shankar, S., Ganapathy, S., and Srivastava, R. K. (2007). Green tea polyphenols: biology and therapeutic implications in cancer. Front. Biosci. 12, 4881-4899. doi: $10.2741 / 2435$

Shi, J., Kantoff, P. W., Wooster, R., and Farokhzad, O. C. (2016). Cancer nanomedicine: progress, challenges and opportunities. Nat. Rev. Cancer 17, 20. doi: $10.1038 /$ nrc. 2016.108

Siegel, R. L., Miller, K. D., and Jemal, A. (2017). Cancer Statistics, 2017. CA Cancer J. Clin. 67, 7-30. doi: 10.3322/caac.21387

Siegelin, M. D., Habel, A., and Gaiser, T. (2008). Epigalocatechin-3-gallate (EGCG) downregulates PEA15 and thereby augments TRAIL-mediated apoptosis in malignant glioma. Neurosci. Lett. 448, 161-165. doi: 10.1016/j. neulet.2008.10.036

Simanshu, D. K., Nissley, D. V., and Mccormick, F. (2017). RAS proteins and their regulators in human disease. Cell 170, 17-33. doi: 10.1016/j.cell.2017.06.009
Singla, A. K., Garg, A., and Aggarwal, D. (2002). Paclitaxel and its formulations. Int. J. Pharm. 235, 179-192. doi: 10.1016/S0378-5173(01)00986-3

Smith, R. A., Andrews, K. S., Brooks, D., Fedewa, S. A., Manassaram-Baptiste, D., Saslow, D., et al. (2017). Cancer screening in the United States, 2017: a review of current American Cancer Society guidelines and current issues in cancer screening. CA Cancer J. Clin. 67, 100-121. doi: 10.3322/caac.21392

Soliman, H., Mediavilla-Varela, M., and Antonia, S. (2010). Indoleamine 2,3-dioxygenase: is it an immune suppressor? Cancer J. 16, 354-359. doi: 10.1097/PPO.0b013e3181eb3343

Song, X., Du, J., Zhao, W., and Guo, Z. (2017). Epigallocatechin-3-gallate(EGCG): mechanisms and the combined applications. Comb. Chem. High Throughput Screen. 20, 872-885. doi: 10.2174/1386207321666171218115850

Suk, J. S., Xu, Q., Kim, N., Hanes, J., and Ensign, L. M. (2016). PEGylation as a strategy for improving nanoparticle-based drug and gene delivery. Adv. Drug Deliv. Rev. 99, 28-51. doi: 10.1016/j.addr.2015.09.012

Sun, M., Wang, K., and Oupicky, D. (2018a). Advances in stimulus-responsive polymeric materials for systemic delivery of nucleic acids. Adv. Healthc. Mater. 7, 1701070. doi: 10.1002/adhm.201701070

Sun, N., Zhao, C., Cheng, R., Liu, Z., Li, X., Lu, A., et al. (2018b). Cargo-free nanomedicine with $\mathrm{pH}$ sensitivity for codelivery of DOX conjugated prodrug with SN38 to synergistically eradicate breast cancer stem cells. Mol. Pharm. 15, 3343-3355. doi: 10.1021/acs.molpharmaceut.8b00367

Tan, S., Zou, C., Zhang, W., Yin, M., Gao, X., and Tang, Q. (2017). Recent developments in d-alpha-tocopheryl polyethylene glycol-succinate-based nanomedicine for cancer therapy. Drug Deliv. 24, 1831-1842. doi: 10.1080/ 10717544.2017.1406561

Tanbour, R., Martins, A. M., Pitt, W. G., and Husseini, G. A. (2016). Drug delivery systems based on polymeric micelles and ultrasound: a review. Curr. Pharm. Des. 22, 2796-2807. doi: 10.2174/1381612822666160217125215

Taurin, S., Nehoff, H., and Greish, K. (2012). Anticancer nanomedicine and tumor vascular permeability; where is the missing link? J. Control. Release 164, 265275. doi: $10.1016 /$ j.jconrel.2012.07.013

Torre, L. A., Islami, F., Siegel, R. L., Ward, E. M., and Jemal, A. (2017). Global cancer in women: burden and trends. Cancer Epidemiol. Biomarkers Prev. 26, 444-457. doi: 10.1158/1055-9965.EPI-16-0858

Tu, S. H., Ku, C. Y., Ho, C. T., Chen, C. S., Huang, C. S., Lee, C. H., et al. (2011). Tea polyphenol (-)-epigallocatechin-3-gallate inhibits nicotine- and estrogen-induced alpha9-nicotinic acetylcholine receptor upregulation in human breast cancer cells. Mol. Nutr. Food Res. 55, 455-466. doi: 10.1002/ mnfr.201000254

Ulbrich, K., and Subr, V. (2004). Polymeric anticancer drugs with pH-controlled activation. Adv. Drug Deliv. Rev. 56, 1023-1050. doi: 10.1016/j.addr.2003.10.040

Uyttenhove, C., Pilotte, L., Theate, I., Stroobant, V., Colau, D., Parmentier, N., et al. (2003). Evidence for a tumoral immune resistance mechanism based on tryptophan degradation by indoleamine 2,3-dioxygenase. Nat. Med. 9, 12691274. doi: $10.1038 / \mathrm{nm} 934$

Van Hooren, L., Georganaki, M., Huang, H., Mangsbo, S. M., and Dimberg, A. (2016). Sunitinib enhances the antitumor responses of agonistic CD40antibody by reducing MDSCs and synergistically improving endothelial activation and T-cell recruitment. Oncotarget 7, 50277-50289. doi: 10.18632/ oncotarget.10364

Vanneman, M., and Dranoff, G. (2012). Combining immunotherapy and targeted therapies in cancer treatment. Nat. Rev. Cancer 12, 237-251. doi: 10.1038/ nrc3237

Wang, J., Li, S., Han, Y., Guan, J., Chung, S., Wang, C., et al. (2018a). Poly(ethylene glycol)-polylactide micelles for cancer therapy. Front. Pharmacol. 9, 202. doi: 10.3389/fphar.2018.00202

Wang, J., Sun, J., Chen, Q., Gao, Y., Li, L., Li, H., et al. (2012). Star-shape copolymer of lysine-linked di-tocopherol polyethylene glycol 2000 succinate for doxorubicin delivery with reversal of multidrug resistance. Biomaterials 33 , 6877-6888. doi: 10.1016/j.biomaterials.2012.06.019

Wang, Y. Q., Lu, J. L., Liang, Y. R., and Li, Q. S. (2018b). Suppressive effects of EGCG on cervical cancer. Molecules 23, E2334. doi: 10.3390/molecules23092334

Wani, M. C., Taylor, H. L., Wall, M. E., Coggon, P., and Mcphail, A. T. (1971). Plant antitumor agents. VI. The isolation and structure of taxol, a novel antileukemic and antitumor agent from Taxus brevifolia. J. Am. Chem. Soc. 93, 2325-2327. doi: $10.1021 /$ ja00738a045 
Wicki, A., Witzigmann, D., Balasubramanian, V., and Huwyler, J. (2015). Nanomedicine in cancer therapy: challenges, opportunities, and clinical applications. J. Control. Release 200, 138-157. doi: 10.1016/j.jconrel.2014.12.030

Xu, J., Zhang, X., Chen, Y., Huang, Y., Wang, P., Wei, Y., et al. (2017). Improved micellar formulation for enhanced delivery for paclitaxel. Mol. Pharm. 14, 31-41. doi: 10.1021/acs.molpharmaceut.6b00581

Yang, C., Wu, T., Qi, Y., and Zhang, Z. (2018a). Recent advances in the application of vitamin E TPGS for drug delivery. Theranostics 8, 464-485. doi: 10.7150/ thno. 22711

Yang, T., Lan, Y., Cao, M., Ma, X., Cao, A., Sun, Y., et al. (2018b). Glycyrrhetinic acid-conjugated polymeric prodrug micelles co-delivered with doxorubicin as combination therapy treatment for liver cancer. Colloids Surf. B Biointerfaces 175, 106-115. doi: 10.1016/j.colsurfb.2018.11.082

Yang, T., Li, F., Zhang, H., Fan, L., Qiao, Y., Tan, G., et al. (2015). Multifunctional pH-sensitive micelles for tumor-specific uptake and cellular delivery. Polym. Chem. 6, 1373-1382. doi: 10.1039/C4PY01403K

Yao, Y. F., Liu, X., Li, W. J., Shi, Z. W., Yan, Y. X., Wang, L. F., et al. (2017). (-)-Epigallocatechin-3-gallate alleviates doxorubicin-induced cardiotoxicity in sarcoma 180 tumor-bearing mice. Life Sci. 180, 151-159. doi: 10.1016/j.lfs. 2016.12.004

Yin, W., Ke, W., Chen, W., Xi, L., Zhou, Q., Mukerabigwi, J. F., et al. (2019). Integrated block copolymer prodrug nanoparticles for combination of tumor oxidative stress amplification and ROS-responsive drug release. Biomaterials 195, 63-74. doi: 10.1016/j.biomaterials.2018.12.032

Yoo, H. S., and Park, T. G. (2004a). Folate-receptor-targeted delivery of doxorubicin nano-aggregates stabilized by doxorubicin-PEG-folate conjugate. J. Control. Release 100, 247-256. doi: 10.1016/j.jconrel.2004.08.017

Yoo, H. S., and Park, T. G. (2004b). Folate receptor targeted biodegradable polymeric doxorubicin micelles. J. Control. Release 96, 273-283. doi: 10.1016/j. jconrel.2004.02.003

Youk, H. J., Lee, E., Choi, M. K., Lee, Y. J., Chung, J. H., Kim, S. H., et al. (2005). Enhanced anticancer efficacy of alpha-tocopheryl succinate by conjugation with polyethylene glycol. J. Control. Release 107, 43-52. doi: 10.1016/j.jconrel.2005.05.014

Youn, Y. S., and Bae, Y. H. (2018). Perspectives on the past, present, and future of cancer nanomedicine. Adv. Drug Deliv. Rev. 130, 3-11. doi: 10.1016/j. addr.2018.05.008

Zamanakou, M., Germenis, A. E., and Karanikas, V. (2007). Tumor immune escape mediated by indoleamine 2,3-dioxygenase. Immunol. Lett. 111, 69-75. doi: 10.1016/j.imlet.2007.06.001

Zhai, Q., Chen, Y., Xu, J., Huang, Y., Sun, J., Liu, Y., et al. (2017). Lymphoma immunochemotherapy: targeted delivery of doxorubicin via a dual functional nanocarrier. Mol. Pharm. 14, 3888-3895. doi: 10.1021/acs.molpharmaceut. $7 \mathrm{~b} 00606$

Zhang, Y., and Zhuo, R. X. (2005). Synthesis and in vitro drug release behavior of amphiphilic triblock copolymer nanoparticles based on poly (ethylene glycol) and polycaprolactone. Biomaterials 26, 6736-6742. doi: 10.1016/j. biomaterials.2005.03.045

Zhang, G., Li, X., Liao, Q., Liu, Y., Xi, K., Huang, W., et al. (2018a). Waterdispersible PEG-curcumin/amine-functionalized covalent organic framework nanocomposites as smart carriers for in vivo drug delivery. Nat. Commun. 9, 2785. doi: 10.1038/s41467-018-04910-5

Zhang, K., Tang, X., Zhang, J., Lu, W., Lin, X., Zhang, Y., et al. (2014a). PEGPLGA copolymers: their structure and structure-influenced drug delivery applications. J. Control. Release 183, 77-86. doi: 10.1016/j.jconrel.2014.03.026

Zhang, P., Lu, J., Huang, Y., Zhao, W., Zhang, Y., Zhang, X., et al. (2014b). Design and evaluation of a PEGylated lipopeptide equipped with drug-interactive motifs as an improved drug carrier. AAPS J. 16, 114-124. doi: 10.1208/s12248-013-9536-9

Zhang, P., Wu, J., Xiao, F., Zhao, D., and Luan, Y. (2018b). Disulfide bond based polymeric drug carriers for cancer chemotherapy and relevant redox environments in mammals. Med. Res. Rev. 38, 1485-1510. doi: 10.1002/med.21485
Zhang, X., Chen, D., Ba, S., Zhu, J., Zhang, J., Hong, W., et al. (2014c). Poly(1histidine) based triblock copolymers: $\mathrm{pH}$ induced reassembly of copolymer micelles and mechanism underlying endolysosomal escape for intracellular delivery. Biomacromolecules 15, 4032-4045. doi: 10.1021/bm5010756

Zhang, X., Huang, Y., and Li, S. (2014d). Nanomicellar carriers for targeted delivery of anticancer agents. Ther. Deliv. 5, 53-68. doi: 10.4155/tde.13.135

Zhang, X., Huang, Y., Zhao, W., Chen, Y., Zhang, P., Li, J., et al. (2014e). PEG-farnesyl thiosalicylic acid telodendrimer micelles as an improved formulation for targeted delivery of paclitaxel. Mol. Pharm. 11, 2807-2814. doi: $10.1021 / \mathrm{mp} 500181 \mathrm{x}$

Zhang, X., Huang, Y., Zhao, W., Liu, H., Marquez, R., Lu, J., et al. (2014f). Targeted delivery of anticancer agents via a dual function nanocarrier with an interfacial drug-interactive motif. Biomacromolecules 15, 4326-4335. doi: 10.1021/bm501339j

Zhang, X., Liu, K., Huang, Y., Xu, J., Li, J., Ma, X., et al. (2014g). Reductionsensitive dual functional nanomicelles for improved delivery of paclitaxel. Bioconjug. Chem. 25, 1689-1696. doi: 10.1021/bc500292j

Zhang, X., Lu, J., Huang, Y., Zhao, W., Chen, Y., Li, J., et al. (2013). PEGfarnesylthiosalicylate conjugate as a nanomicellar carrier for delivery of paclitaxel. Bioconjug. Chem. 24, 464-472. doi: 10.1021/bc300608h

Zhang, Y., Huang, Y., and Li, S. (2014h). Polymeric micelles: nanocarriers for cancer-targeted drug delivery. AAPS PharmSciTech 15, 862-871. doi: 10.1208/ s12249-014-0113-Z

Zhang, Y., Huang, Y., Zhao, W., Lu, J., Zhang, P., Zhang, X., et al. (2014i). Fmocconjugated PEG-vitamin E2 micelles for tumor-targeted delivery of paclitaxel: enhanced drug-carrier interaction and loading capacity. AAPS J. 16, 12821291. doi: 10.1208/s12248-014-9651-2

Zhang, Z., Tan, S., and Feng, S. S. (2012). Vitamin E TPGS as a molecular biomaterial for drug delivery. Biomaterials 33, 4889-4906. doi: 10.1016/j. biomaterials.2012.03.046

Zhao, D., Liu, N., Shi, K., Wang, X., and Wu, G. (2015). Preparation of a multifunctional verapamil-loaded nano-carrier based on a self-assembling PEGylated prodrug. Colloids Surf. B Biointerfaces 135, 682-688. doi: 10.1016/j. colsurfb.2015.08.018

Zhao, M., Huang, Y., Chen, Y., Xu, J., Li, S., and Guo, X. (2016). PEG-Fmocibuprofen conjugate as a dual functional nanomicellar carrier for paclitaxel. Bioconjug. Chem. 27, 2198-2205. doi: 10.1021/acs.bioconjchem.6b00415

Zhou, Q., Zhang, L., Yang, T., and Wu, H. (2018a). Stimuli-responsive polymeric micelles for drug delivery and cancer therapy. Int. J. Nanomed. 13, 2921-2942. doi: 10.2147/IJN.S158696

Zhou, Y., Yu, F., Zhang, F., Chen, G., Wang, K., Sun, M., et al. (2018b). Cyclammodified PEI for combined VEGF siRNA silencing and CXCR4 inhibition to treat metastatic breast cancer. Biomacromolecules 19, 392-401. doi: 10.1021/ acs.biomac.7b01487

Zhu, M. M. T., Dancsok, A. R., and Nielsen, T. O. (2019). Indoleamine dioxygenase inhibitors: clinical rationale and current development. Curr. Oncol. Rep. 21, 2. doi: 10.1007/s11912-019-0750-1

Zunino, F., and Pratesi, G. (2004). Camptothecins in clinical development. Expert Opin. Investig. Drugs 13, 269-284. doi: 10.1517/13543784.13.3.269

Conflict of Interest Statement: The authors declare that the research was conducted in the absence of any commercial or financial relationships that could be construed as a potential conflict of interest.

Copyright (c) 2019 Li, Zhang, Liu and He. This is an open-access article distributed under the terms of the Creative Commons Attribution License (CC BY). The use, distribution or reproduction in other forums is permitted, provided the original author(s) and the copyright owner(s) are credited and that the original publication in this journal is cited, in accordance with accepted academic practice. No use, distribution or reproduction is permitted which does not comply with these terms. 